\title{
Political competition and Mirrleesian income taxation: A first pass*
}

\author{
Felix J. Bierbrauer ${ }^{\dagger}$ and Pierre C. Boyer ${ }^{\ddagger}$ \\ January 5, 2012
}

\begin{abstract}
We study political competition in a simple Mirrleesian model of income taxation. The analysis is made tractable by exploiting the mechanism design formulation of the Mirrleesian problem. We consider basic variants of the Downsian model such as vote-share maximizing politicians, a winner-take-all system, and competition among politicians who differ in a quality dimension. We focus on the welfare implications of political competition and its implications for tax rates. In particular, we clarify the conditions under which equilibrium tax policies are Pareto-efficient and the conditions under which political failures in the sense of Besley and Coate (1998) arise.
\end{abstract}

Keywords: Political Competition; Non-linear Income Taxation.

JEL classification: C72; D72; H21.

${ }^{*}$ We thank Toke Aidt, Rafael Aigner, Sophie Bade, Marcus Berliant, Marco Battaglini, Georges Casamatta, Guillaume Cheikbossian, Helmuth Cremer, Carlos da Costa, Philippe De Donder, Christoph Engel, Vincenzo Galasso, Hans Peter Grüner, Emanuel Hansen, Martin Hellwig, Arye Hillman, Michel Le Breton, Alessandro Lizzeri, David Martimort, Matthias Messner, Georg Nöldeke, Elisabeth Schulte, Karine Van der Straeten, and Christian Traxler for very helpful comments and discussions, as well as participants at the 19th Workshop on Political Economy in Silvaplana, CESifo Area Conference on Public Sector Economics 2011, PET 2011 in Bloomington, Econometric Society North American Summer Meeting in St. Louis, EEA-ESEM 2011, German Economic Association 2011, AFSE 2011, UECE 2011, and seminar participants at Basel, IGIER (Bocconi University), Mannheim, St. Gallen, and the Toulouse School of Economics. The second author gratefully acknowledges the European Science Foundation research networking programme Public Goods, Public Projects, Externalities, the Max Planck Institute for Research on Collective Goods, and the Collaborative Research Center 884 for financial support. This research was partly carried out while the second author was at the Toulouse School of Economics. The second author also thanks the Max Planck Institute for Research on Collective Goods and the IGIER at Bocconi University for their hospitality. The usual disclaimer applies.

${ }^{\dagger}$ University of Cologne. E-mail: bierbrauer@wiso.uni-koeln.de

${ }^{\ddagger}$ University of Mannheim, Department of Economics. E-mail: pierre.boyer@uni-mannheim.de 


\section{Introduction}

The Mirrlees (1971)-model of optimal income taxation has become one of the workhorses in public economics. In this model, a social planner chooses a redistributive tax policy subject to a public sector budget constraint and incentive constraints which take the behavioral responses of individuals to the proposed tax schedule into account. Other than incentive compatibility and physical feasibility there are no further constraints. An optimal income tax in the Mirrleesian model is therefore the theoretical benchmark for any normative model of redistributive taxation. This paper is a first attempt to understand the tax policies that arise if we replace the benevolent social planner of the Mirrleesian model by the forces of political competition; i.e., we study a model of Downsian competition in which politicians propose tax policies.

Our focus is on the welfare implications of political competition. Besley (2006) emphasizes the importance of "welfare theorems" for models of political competition, in analogy to the classical welfare theorems which refer to competitive market allocations. Our paper contributes to this programme by looking at basic variants of the Downsian model such as competition between vote-share maximizing politicians, political competition in a winner-take-all system, and political competition among politicians who differ in a quality dimension. Our main results will characterize to what extent such political equilibria give rise to inefficiencies that can be interpreted as political failures in the sense of Besley and Coate (1998). Moreover, we will compare the welfare implications of vote-share-maximizing behavior and of behavior under a winner-take-all system.

We view our paper as a first attempt because it is based on the simplest possible version of the Mirrleesian model: the economy consists of high-skilled and low-skilled individuals. High-skilled individuals have a comparatively low cost of productive effort, so that, when confronted with an income tax schedule, these individuals choose a high level of effort and therefore end up being richer - in the sense of having more pre- and after-tax income - than the low-skilled individuals. We assume that the economy has more low-skilled (cf. poor) than high-skilled (cf. rich) agents.

For the normative analysis of the Mirrleesian model, the two-type has strengths and weaknesses. The major weakness is that one does not get to a characterization of an optimal income tax that is meaningful in a quantitative sense. The real world obviously knows more than two income levels $]^{1}$ The major strength is that one obtains an understanding of the Mirrleesian model from the perspective of allocation theory. In particular, the two type model facilitates an understanding of the basic equity-efficiency trade-off,

\footnotetext{
${ }^{1}$ Starting with Mirrlees (1971), there have been various attempts to numerically compute optimal income taxes for economies with many possible income levels. Recent contributions include Saez (2001) and Brewer, Saez and Shephard (2010).
} 
e.g. to answer the question why a distortionary tax system can be welfare-maximizing, even though first-best allocations are in the feasible set. The same issues arise when we try to understand the welfare implications of political competition. We will not get to an equilibrium characterization of income tax schedules that can be easily compared to those that we find in the real-world. However, we will get qualitative properties about the political equilibria tax rates and we can expect clear answers to questions of the following sort: Does political competition yield Pareto-efficient tax structures? Or, which Pareto-efficient tax structures can be reached by means of political competition?

The main part of our formal analysis is based on the assumption that politicians behave in a vote-share-maximizing way. This assumption more closely portrays political systems based on proportional representation $2^{2}$ We will also compare our findings to the equilibria that we obtain under the assumption that politicians seek to maximize their winning probabilities, which may be descriptive of majoritarian political systems. Finally, we provide a welfare analysis of the equilibria and their implications for the tax rates in the two regimes.

Our first main result characterizes the outcome of political competition between two identical vote-share-maximizing politicians: there is a unique equilibrium and both politicians choose the tax policy which maximizes the well-being of the larger group, i.e., the low-skilled agents. Hence, the assumption that the majority of the population is lowskilled implies that the equilibrium outcome under Downsian competition is the tax policy that would be chosen by a Rawlsian social planner in a normative model of income taxation. The logic is familiar from the basic textbook model of Bertrand competition. Suppose one politician proposed a tax policy different from the Rawlsian one, then the other politician can offer a policy that is more attractive to the larger group of low-skilled agents and thereby win a majority of votes. Hence, a politician who does not propose the Rawlsian tax policy is akin to a firm with a price above the marginal cost in the basic Bertrand model. Such a firm is vulnerable to undercutting by its competitor.

Secondly, we consider the possibility that there is a quality difference between the politicians, i.e., everything else being equal, one politician is more appealing to the voters. It has been argued (see, e.g., Besley, 2005; Galasso and Nannicini, 2011) that differences in popularity, competence assessments or charisma of different politicians are, in an empirical sense, essential to understanding the outcomes of political competition 3

\footnotetext{
${ }^{2}$ See Lijphart (1999) for a description of political systems.

${ }^{3}$ There are two possible interpretations of a quality difference in our model: (i) The good politician is a more efficient manager of the government, i.e., anything else being equal, he is capable of running the government at lower cost and therefore has a lower revenue requirement in the government budget constraint; (ii) the good politician is more appealing to voters in some dimension which has no bearing
} 
Introducing such a quality difference in our model leads to a strikingly different set of equilibrium outcomes. The political equilibrium under the assumption that one politician has a quality advantage is as follows: there is a unique mixed-strategy equilibrium. In such an equilibrium, both politicians win the election with positive probability. The most likely policy proposal of the bad politician is the tax policy that is most attractive to the rich and least attractive to the poor. The most likely proposal of the good politician is the one which maximizes the well-being of the rich, subject to the constraint that the bad politician cannot make a proposal that is more attractive to the poor. Again, there is an analogy to models of Bertrand competition. If there are two firms who compete in prices but differ in their marginal cost, then the firm with a cost advantage will set a limit price, which is the maximal price that makes undercutting unprofitable for the competitor. Here, the good politician proposes a "limit tax policy" with the property that the bad politician cannot make a proposal that is more attractive to a majority of voters.

However, this is not the only force that is effective in equilibrium: given that the good politician proposes the limit tax policy with a high probability, the bad politician wants to make sure that he gets at least the votes of the rich. Since he is disadvantaged, he can do so only if he differentiates himself sufficiently from the good politician, and therefore he has to propose a tax policy that is much more attractive to the rich than the proposal made by his competitor. Now, given that the bad politician goes for the rich, the good politician has an incentive to "chase" him; that is, to propose a tax policy that is equally appealing to the rich, but leaves more utility to the poor, and thereby to win the votes of all voters, as opposed to a majority. However, if the good politician engages in chasing, he becomes vulnerable to undercutting by the bad politician, who may then deviate to a proposal that attracts the majority of poor voters. Hence, in the mixedstrategy equilibrium, the good politician's strategy is a compromise between the limit tax policy which avoids undercutting and the possibility of getting a larger vote share by chasing the bad politician. The bad politician's strategy is a compromise between the desire to "run away" from the limit tax policy, so as to get at least the votes of the rich and the prospect of gaining a majority of votes by undercutting, which is profitable whenever the good politician engages in chasing.

Our equilibrium characterization gets particularly sharp for the limit case which is obtained by making the quality difference between the two politicians arbitrarily small: In the limit, the good politician proposes the Rawlsian tax policy with probability 1 , whereas the bad politician's most likely proposal is the "Anti-Rawlsian" tax policy, i.e., the tax policy that is most attractive to the rich. Hence, with a quality difference aron government finances, e.g., he is more charismatic. 
bitrarily close to, but different from, zero, the bad politician "specializes" on proposals that are more attractive to the high-skilled and the good politician "specializes" on those that are more attractive to the low-skilled. Consequently, the polarization becomes very large and the equilibrium looks as if proposals were made by two ideological parties, one party catering to the rich and the other party catering to the poor.

These results are interesting because they provide answers to the following questions: is the outcome of political competition Pareto-efficient (in the set of incentive-compatible and resource-feasible tax policies), i.e., does a version of the first welfare theorem hold? If so, which Pareto-efficient outcomes can be reached, if we replace the fictitious social planner of the normative theory by the forces of political competition? Put differently, does a version of the second welfare theorem hold in models of political competition?

Our analysis provides answers to both of these questions. In the symmetric version of our model, the answer to the first question is "yes". Vote-share-maximizing politicians will not waste utility possibilities because these could be turned into additional votes. The answer to the second question is more interesting: political competition selects an outcome that is very different from the one that would be chosen by the utilitarian social planner, on which the original treatment of Mirrlees (1971) was based. While a utilitarian planer trades off the utility of the rich and the utility of the poor, the outcome under political competition is the Rawlsian tax policy with no concern for the well-being of the rich.

If there is a quality difference between the two politicians, then there is the possibility of a political failure in the sense of Besley and Coate (1998): the bad politician wins an election with positive probability. Whenever this happens, then, from an ex post perspective, there exists a Pareto-improving policy change since the good politician would be capable of generating the same utility for the rich, and give a strictly higher utility level to the poor. At the same time, however, we cannot Pareto-rank the efficient equilibrium allocation in the symmetric model and the inefficient equilibrium allocation in the asymmetric model: the presence of a bad politician implies that the minority of rich agents is better off than they would be in the equilibrium of the symmetric model; that is, they benefit from the presence of a bad politician.

A similar conclusion arises from the comparison of the political equilibrium under the assumption that politicians engage in vote-share maximization and the equilibrium under the assumption that politicians maximize their winning probabilities. In the latter case, political failures are avoided. The good politician wins the election with probability 1 . Since he does not care for his margin of victory, his sole concern is to make sure that his inferior opponent cannot gain a majority of votes by means of undercutting. As a 
consequence, there is no way of Pareto-improving upon the equilibrium policy. Under vote-share-maximization, by contrast, the good politician also chooses policy proposals with an eye towards the possibility of gaining the votes of the rich. While this implies that the bad politician wins occasionally, and hence, a political failure, the rich may benefit from this, in the sense that their expected utility in the "vote-share equilibrium" is higher than their expected utility in the "winner-take-all-equilibrium".

The political equilibria under the two systems have qualitative implications for the tax rates. If politicians differ in competence, political equilibria under majoritarian system have higher expected tax rates than the one under proportional representation. Redistribution towards the larger group, i.e., the low-skilled agents, is then exacerbated under majoritarian system. This confirms previous findings showing that majoritarian systems are associated with larger government and favor targeted redistribution towards a narrow constituency compared to proportional systems (see Persson and Tabellini, 2000; Lizzeri and Persico, 2001).

Finally, Downsian models of political competition are known and criticized for their convergence results. In our model of Downsian competition, an arbitrarily small quality difference between the two politicians suffices to break this result. Even though political parties are assumed to be opportunistic vote-share maximizers, the equilibrium looks as if we had two ideological parties, one targeting the votes of the poor, the other one targeting the votes of the rich. Similar observations have been made in the literature, albeit not in the context of a Mirrleesian model of income taxation.

The remainder is organized as follows. The next section contains a discussion of related literature. Section 3 specifies the basic model, which assumes vote-share-maximizing politicians, and introduces a mechanism design approach which renders the equilibrium characterization tractable. Section 4 contains the results of the equilibrium analysis. In Section 5, we show how the results change if politicians maximize winning probabilities rather than vote shares and provide a discussion of the welfare implications of political competition in different political systems. The last section contains concluding remarks.

\section{Related literature}

Our work is related to various strands of the literature.

There is a literature on the political economy of redistributive income taxation (see Persson and Tabellini, 2000). Following the approach to political competition developed by Downs (1957), Roberts (1977) discusses the existence of pure strategy Nash equilibria in the model of optimal linear income taxation due to Sheshinski (1972), which restricts 
attention to affine income tax schedules. Meltzer and Richard (1981) use this framework to develop a positive theory of the size of government. Roemer (1999) and De Donder and Hindriks (2003) study Downsian competition under the assumption that the income tax function is quadratic.

The strength of these models is to provide positive explanations for income tax policies. Nevertheless, it is unsatisfactory that political economy approaches to income taxation often invoke functional form assumptions, whereas normative approaches seek to avoid such assumptions. This is worrisome, because the differences in the modeling of feasible policies make it difficult to answer the classical question of welfare economics when assessing the outcomes of political competition. Our contribution is that we analyze political competition with no a priori restriction on the set of admissible income tax schedules. This line of research has been recently pursued by Roemer (2011a) and Bohn and Stuart (2011). Roemer (2011a) and Bohn and Stuart (2011) study a model of political competition in a Mirrleesian income tax framework. However, they are not concerned with political competition à la Downs. Roemer (2011a) uses a Party Unanimity Nash Equilibrium as solution concept (see Roemer, 1999) and Bohn and Stuart (2011) follows the representative-democracy approach (see Osborne and Slivinski, 1996; Besley and Coate, 1997).

Second, there is a literature on the political economy of distributive politics. This literature is based on exchange economies, i.e., production is not endogenous. Distributive politics therefore takes the form of a "divide the dollar"-game in which a policy proposal specifies how a cake of a given size should be distributed among voters. Examples of this approach include Myerson (1993), Lizzeri and Persico (2001), Laslier and Picard (2002), Carbonell-Nicolau and Ok (2007), Crutzen and Sahuguet (2009), Casamatta, Cremer and De Donder (2010), and Roemer (2011b). This literature has some similarities with our approach. First, the policy domain is of a high dimension, which implies that pure strategy equilibria do not exist, so that one has to focus on mixed strategy equilibria. Second this literature makes no functional form assumptions on admissible policies. The difference to our approach lies in the fact that we have endogenous production, which implies that distributive policies have repercussions for the size of the cake that is going to be available for redistribution.

Third, there is a recent literature which attempts to link normative public finance and political economics. This literature has so far focused on dynamic models of taxation, and on political economy approaches that differ from the one by Downs (1957) 4 Our

\footnotetext{
${ }^{4}$ Acemoglu, Golosov and Tsyvinski (2008; 2010) study optimal taxation in a dynamic model subject to the constraint that a selfish politician is willing to propose this policy. For this purpose, they make use of the Barro (1973) and Ferejohn (1986) model, in which voters are able to discipline politicians who would
} 
paper contributes to this research program by performing the most basic exercise one could think of: an analysis of Downsian competition in a static Mirrleesian model of income taxation.

Finally, our paper is related to the studies of political competition under the assumption that the parties are not completely symmetric, but differ in a quality dimension, named "valence". Various authors have introduced such differences into formal models of political competition. Examples include Adams (1999), Ansolabehere and Snyder (2000), Groseclose (2001), Aragones and Palfrey (2002), Sahuguet and Persico (2006), and Krasa and Polborn (2009). The paper that is closest to us is Aragones and Palfrey (2002). In particular, the logic of the equilibrium analysis when an advantaged politician runs against a disadvantaged politician is similar. There are, however, also some important differences which include the following: Aragones and Palfrey (2002) work with an abstract policy domain, as opposed to Mirrleesian income tax schedules; their equilibrium characterization is not based on the iterated elimination of weakly dominated strategies; finally, our equilibrium characterization does not require that the quality difference is bounded.

\section{The model}

The Environment. A voter $i$ has utility function $U_{i}=u\left(c_{i}\right)-l_{i}$, where $c_{i}$ is $i$ 's consumption of a private good and $l_{i}$ denotes hours worked by voter $i$. Voters differ in their productive abilities. Each voter has private information about his skill parameter $w_{i}$, where $w_{i} \in\left\{w_{L}, w_{H}\right\}$ with $0<w_{L}<w_{H}$. There is a continuum of voters of mass 1. The population share of voters with a high skill level (respectively low skill level) is commonly known and denoted by $f_{H}$ (resp. $f_{L}=1-f_{H}$ ). We assume that the majority of the population has a low skill level, $0<f_{H}<\frac{1}{2}$. We also assume in the following that $1 \geq f_{H} \frac{w_{H}}{w_{L}} !^{5}$

Output can be produced according to two constant returns to scale technologies. If an individual with productivity $w_{t}, t \in\{L ; H\}$, works for one hour, then this yields $w_{t}$ units of output. We denote the output that is provided by voter $i$ in the following by $y_{i}$, where $y_{i}=w_{i} l_{i}$. We can hence write a voter's utility function as $U_{i}=u\left(c_{i}\right)-\frac{y_{i}}{w_{i}}$. The

otherwise run away with the economy's resources. Battaglini and Coate (2008) study a dynamic model of Ramsey taxation and public-goods provision in connection with a legislative bargaining procedure à la Baron and Ferejohn (1989). Fahri and Werning (2008) study the taxation of capital income in the probabilistic voting model by Lindbeck and Weibull (1987). Martimort (2001) studies strategic budget deficits and optimal taxation in a model with partisan politics.

${ }^{5}$ This assumptions simplifies the exposition. It implies that non-negativity constraints on consumption levels can be safely ignored; see Bierbrauer and Boyer (2010) for details. 
function $u($.$) satisfies u^{\prime}()>0,. u^{\prime \prime}()<0,. \lim _{c \rightarrow 0} u^{\prime}(c)=\infty$, and $\lim _{c \rightarrow \infty} u^{\prime}(c)=0$.

Utility Promises as the Policy Domain. In the original treatment of Mirrlees (1971), voters face an income tax schedule $T: \mathbb{R}_{+} \rightarrow \mathbb{R}$ that relates their pre-taxincome, $y$, to their after-tax-income, $c$, and then choose their productive effort in a utility-maximizing way. That is, individuals solve the following utility maximization problem,

$$
U(w \mid T):=\max _{c, y} u(c)-\frac{y}{w} \text { s.t. } c=y-T(y)
$$

Intuitively, we can now think of two competing politicians, indexed by $j \in\{0,1\}$, as proposing different income tax schedules, and of voters as supporting the politicians under whose income tax policy they would fare better. However, we will not formalize this problem. Instead, we follow the recent literature on optimal income taxation and take an indirect approach to the characterization of equilibrium tax policies. More specifically, we use a mechanism design approach to make the analysis of political competition tractable: as a first step, we will characterize the real allocations - consisting of consumption levels and output choices - that are induced by some proposed income tax schedules. We will then, as a second step, establish a one-to-one relationship between these allocations and the payoffs of high-skilled and low-skilled individuals, respectively. As will become clear, this makes it possible to reformulate a game of political competition over non-linear income tax schedules as a game in which politicians compete on the basis of promised utility levels $\sqrt[6]{6}$ The latter game has a one-dimensional policy space which makes the analysis tractable. Below we will explain how utility promises can be mapped back into income tax policies.

The Taxation Principle, a well-known result (see, e.g., Guesnerie, 1995), implies that, instead of assuming that politician $j$ proposes an income tax schedule $T^{j}$, we may equivalently assume that he specifies an allocation consisting of a consumption-output bundle for low-skilled individuals, $\left(c_{L}^{j}, y_{L}^{j}\right)$, and a consumption-output bundle for high-skilled individuals, $\left(c_{H}^{j}, y_{H}^{j}\right)$ subject to incentive compatibility constraints and a resource constraint. The incentive compatibility constraints are

$$
u\left(c_{H}^{j}\right)-\frac{y_{H}^{j}}{w_{H}} \geq u\left(c_{L}^{j}\right)-\frac{y_{L}^{j}}{w_{H}},
$$

\footnotetext{
${ }^{6}$ Our political game can be seen as a game where two mechanism designers (politicians or principals) offer mechanisms to privately informed voters (agents). Competition between multi-principals has been studied in the common agency literature (for a survey see Martimort, 2006). Our framework differs from the standard common agency game in important dimensions: we do not have multi-contracting issues, contracts offered are anonymous, and the choice of the voters are unobserved by the politicians.
} 
and

$$
u\left(c_{L}^{j}\right)-\frac{y_{L}^{j}}{w_{L}} \geq u\left(c_{H}^{j}\right)-\frac{y_{H}^{j}}{w_{L}} .
$$

The resource constraint is

$$
f_{H}\left(y_{H}^{j}-c_{H}^{j}\right)+f_{L}\left(y_{L}^{j}-c_{L}^{j}\right) \geq b^{j}
$$

The parameter $b^{j}$ is a revenue requirement in politician $j \in\{0,1\}$ 's public sector budget constraint. We allow these requirements to differ across politicians and adopt the following normalizations, $b^{0}=0$ and $b^{1} \geq 0$. We interpret $b^{j}$ as a quality measure. A good politician runs the government at a low cost and therefore needs to extract lower tax payments from individuals. Under the assumption that $b^{0} \neq b^{1}$, our analysis gives rise to a model of political competition between a good and a bad politician. $]^{7}$

We can now simplify the analysis further based on the observation that a vote-share maximizer will propose an allocation that is Pareto-efficient in the set allocations satisfying (2) - (4). To characterize the set of Pareto-efficient allocations, we study a family of optimization problems, which depend on two parameters, namely the revenue requirement of politician $j, b^{j}$, and a given utility level for the low-skilled voters,

$$
u\left(c_{L}^{j}\right)-\frac{y_{L}^{j}}{w_{L}}=v_{L}^{j}
$$

We denote the set of allocations satisfying (2) - (5) by $\mathcal{A}\left(v_{L}^{j}, b^{j}\right)$. We can now define the set of Pareto-efficient allocations with respect to the value function $V_{H}:\left(v_{L}^{j}, b^{j}\right) \mapsto V_{H}\left(v_{L}^{j}, b^{j}\right)$ of the following optimization problem:

$$
V_{H}\left(v_{L}^{j}, b^{j}\right):=\max u\left(c_{H}^{j}\right)-\frac{y_{H}^{j}}{w_{H}} \quad \text { s.t. }\left(c_{L}^{j}, y_{L}^{j}, c_{H}^{j}, y_{H}^{j}\right) \in \mathcal{A}\left(v_{L}^{j}, b^{j}\right) \text {. }
$$

A solution to this problem is a Pareto-efficient allocation if and only if the utility promise to the low-skilled, $v_{L}^{j}$, is such that

$$
\frac{\partial}{\partial v_{L}^{j}} V_{H}\left(v_{L}^{j}, b^{j}\right)<0
$$

The graph of the function $V_{H}\left(\cdot, b^{j}\right)$, over the range where 7 holds, is the Pareto-frontier, i.e., the frontier of the set of possible utility promises by politician $j$ to low-skilled and high-skilled individuals.

\footnotetext{
${ }^{7}$ In the Appendix we argue that a model in which the quality difference is unrelated to economic outcomes, e.g., because one politician appears to be more charismatic than his competitor as in the valence literature, is mathematically equivalent to the present formulation where a better politician is associated with lower government consumption.
} 
Figure 1 illustrates the properties of the Pareto-frontier graphically $]^{8}$ The essential one for the purposes of the equilibrium analysis is the following: for each politician $j$, there is a minimal and maximal utility promise to the low-skilled voters; henceforth denoted by $\underline{v}_{L}\left(b^{j}\right)$ and $\bar{v}_{L}\left(b^{j}\right)$, respectively. If politician 0 has a quality advantage, he can promise more utility to the low-skilled,

$$
\bar{v}_{L}(0)>\bar{v}_{L}\left(b^{1}\right) .
$$

Also, the worst promise by a competent politician is more attractive than the worst promise by a incompetent politician,

$$
\underline{v}_{L}(0)>\underline{v}_{L}\left(b^{1}\right) \text {. }
$$

A symmetric argument applies to the possible utility promises to high-skilled individuals; hence,

$$
V_{H}\left(\underline{v}_{L}(0), 0\right)>V_{H}^{j}\left(\underline{v}_{L}\left(b^{1}\right), b^{1}\right) \quad \text { and } \quad V_{H}\left(\bar{v}_{L}(0), 0\right)>V_{H}^{j}\left(\bar{v}_{L}\left(b^{1}\right), b^{1}\right) .
$$

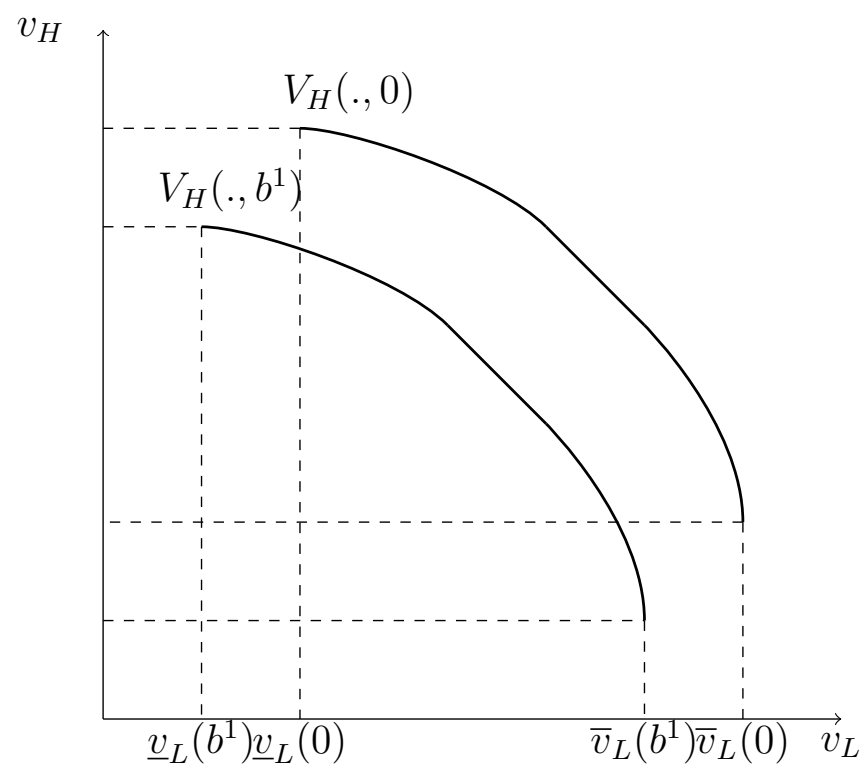

Figure 1: The Politicians' second-best Pareto-Frontiers when $0=b^{0}<b^{1}$.

Every point on the Pareto-frontier - which describes possible utility levels of lowskilled and high-skilled individuals - is associated with a Pareto-efficient allocation; i.e., a specification of consumption and output levels for high- and low-skilled individuals. We can therefore take politician $j$ 's set of pure strategies to be

$$
S^{j}=S\left(b^{j}\right)=\left[\underline{v}_{L}\left(b^{j}\right), \bar{v}_{L}\left(b^{j}\right)\right] .
$$

\footnotetext{
${ }^{8}$ The incentive compatibility constraints imply that $v_{H}>v_{L}$ for every point on the Pareto-frontier. The numerical values on the horizontal axis are therefore different from those on the vertical axis. A complete analytical characterization can be found in Bierbrauer and Boyer (2010).
} 
If $j$ chooses some utility promise to the low-skilled, $v_{L}^{j}$, from $S^{j}$, it is understood that the utility promise to high-skilled individuals is given by $v_{H}^{j}=V_{H}\left(v_{L}^{j}, b^{j}\right)$.

Implications for tax rates. The presence of incentive compatibility constraints in the Mirrleesian model of income taxation implies that taxation is distortionary in the following two senses: (i) The Pareto-frontier is concave, and (ii) in the region where the Pareto-frontier is strictly concave, there is an implicitly defined marginal income tax rate that is different from zero. As we discuss below these two observations are in fact equivalent. $9^{9}$

In the Mirrleesian model of income taxation, utility is no longer perfectly transferable between high-skilled and low-skilled individuals, which is reflected in the shape of the second-best Pareto-frontier, relative to a first-best Pareto-frontier which is based on the assumption that skill levels are publicly observable, so that incentive compatibility constraints can be ignored. As soon as one of the incentive constraints is binding, the second best-frontier is strictly concave, whereas the first-best frontier is linear. This is illustrated by Figure 2 .

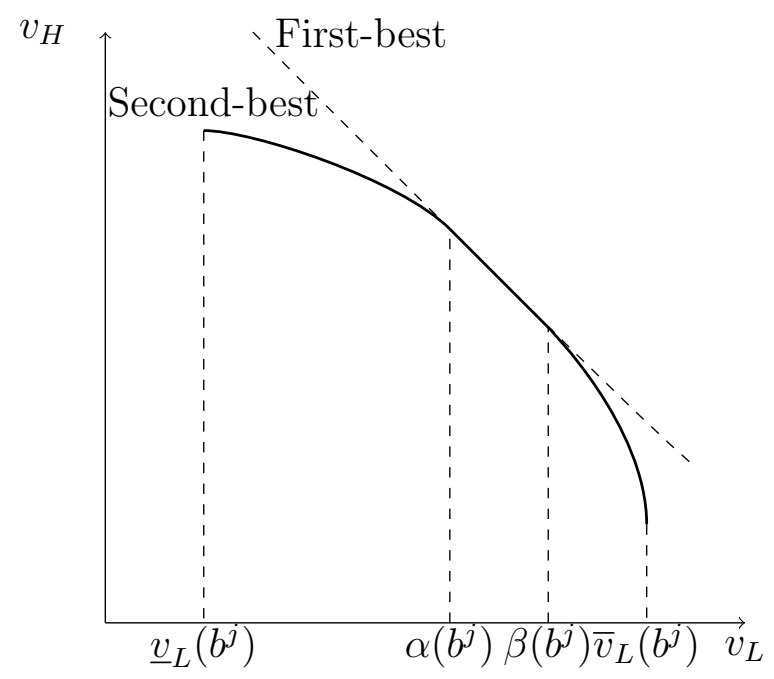

Figure 2: Pareto-Frontiers.

The figure shows that, for given $b^{j}$, there exist numbers $\underline{v}_{L}\left(b^{j}\right)$ and $\bar{v}_{L}\left(b^{j}\right)$ so that $V_{H 1}\left(v_{L}^{j}, b^{j}\right)<0$ if and only if $v_{L} \in\left[\underline{v}_{L}\left(b^{j}\right), \bar{v}_{L}\left(b^{j}\right)\right]$. Moreover, there exist numbers $\alpha\left(b^{j}\right)$, and $\beta\left(b^{j}\right)$ with $\underline{v}_{L}\left(b^{j}\right)<\alpha\left(b^{j}\right)<$ $\beta\left(b^{j}\right)<\bar{v}_{L}\left(b^{j}\right)$, so that: (a) for $v_{L} \in\left[\underline{v}_{L}\left(b^{j}\right), \alpha\left(b^{j}\right)[\right.$, the low-skilled individuals' incentive constraint (3) is binding; (b) for $v_{L} \in\left[\alpha\left(b^{j}\right), \beta\left(b^{j}\right)\right]$, no incentive constraint is binding; (c) for $\left.\left.v_{L} \in\right] \beta\left(b^{j}\right), \bar{v}_{L}\left(b^{j}\right)\right]$, the high-skilled individuals' incentive constraint (2) is binding.

We now describe the relationship between the Pareto-frontier and income tax rates.

\footnotetext{
${ }^{9} \mathrm{~A}$ formal proof can be found in Bierbrauer and Boyer (2010).
} 
To any point on the Pareto-frontier corresponds the allocation

$$
a\left(v_{L}^{j}, b^{j}\right)=\left(c_{L}\left(v_{L}^{j}, b^{j}\right), y_{L}\left(v_{L}^{j}, b^{j}\right), c_{H}\left(v_{L}^{j}, b^{j}\right), y_{H}\left(v_{L}^{j}, b^{j}\right)\right),
$$

which solves Problem (6). Following the literature, we interpret the difference between an individual's marginal rate of transformation between output $y$ and consumption $c$, which equals 1 for each individual, and the individual's marginal rate of substitution, $\frac{1}{w u^{\prime}(c)}$, as the marginal income tax rate that the individual faces ${ }^{10}$ With reference to the allocation $a\left(v_{L}^{j}, b^{j}\right)$, we therefore define the marginal tax rates for high-skilled and low-skilled individuals, respectively, as follows:

$$
\tau_{H}\left(v_{L}^{j}, b^{j}\right):=1-\frac{1}{w_{H} u^{\prime}\left(c_{H}\left(v_{L}^{j}, b^{j}\right)\right)} \text { and } \tau_{L}\left(v_{L}^{j}, b^{j}\right):=1-\frac{1}{w_{L} u^{\prime}\left(c_{L}\left(v_{L}^{j}, b^{j}\right)\right)} .
$$

Similarly, we define the average tax rates associated with $a\left(v_{L}^{j}, b^{j}\right)$ as

$$
A T_{H}\left(v_{L}^{j}, b^{j}\right):=\frac{y_{H}\left(v_{L}^{j}, b^{j}\right)-c_{H}\left(v_{L}^{j}, b^{j}\right)}{y_{H}\left(v_{L}^{j}, b^{j}\right)} \text { and } A T_{L}\left(v_{L}^{j}, b^{j}\right):=\frac{y_{L}\left(v_{L}^{j}, b^{j}\right)-c_{L}\left(v_{L}^{j}, b^{j}\right)}{y_{L}\left(v_{L}^{j}, b^{j}\right)} .
$$

Every point on the Pareto-frontier is associated with marginal income tax rates for high- and low-skilled such that both marginal tax rates are non-decreasing functions of $v_{L}$. We also have that $\tau_{H}\left(v_{L}^{j}, b^{j}\right) \leq 0$ and that $\tau_{L}\left(v_{L}^{j}, b^{j}\right) \geq 0$, for all $v_{L}^{j}$ and $b^{j}$.

Both the sign and the comparative statics properties of the marginal income tax rates depend on which incentive constraint is binding. More precisely, if the low-skilled are very badly off, their incentive constraint is binding, which implies an upward distortion of labor supply for the high-skilled, $\tau_{H}<0$, and no distortionary taxation of low-skilled labour, $\tau_{L}=0$. Moreover, as the low-skilled are made better off, the upward distortion of high-skilled labor supply becomes smaller and smaller, so that $\tau_{H 1}>0$. In the range where no incentive constraint binds, there are no distortions at all, i.e., both marginal tax rates are equal to 0 . Finally, if the low-skilled individuals' utility level is very high, and hence the high-skilled individual's utility level very low, the high-skilled individuals' incentive constraint is binding. This yields a downward distortion of the supply of lowskilled labor, $\tau_{L}>0$, and no distortion of high-skilled labor supply, $\tau_{H}=0$. Moreover, the downward distortion gets more severe as we make the low-skilled individuals even better off, $\tau_{L 1}>0$. The larger the concern for the low-skilled, or the larger the demand for redistribution, the more distortionary taxation will be needed.

Figures 3 and 4 illustrate that to every utility promise to the low-skilled along the Pareto-frontier, there is an implicitly defined tax policy. The figures depict the marginal and average tax rates for a specific example with $u(c)=\sqrt{c}, f_{H}=\frac{1}{3}, w_{L}=1$ and $w_{H}=\frac{5}{4}$.

\footnotetext{
${ }^{10}$ This interpretation is based on the first-order condition of the utility maximization problem that individuals face when confronted with an income tax schedule $T$ : choose $c$ and $y$ in order to maximize $u(c)-\frac{y}{w}$ subject to the constraint $c=y-T(y)$. The first order condition is $T^{\prime}(y)=1-\frac{1}{w u^{\prime}(c)}$.
} 


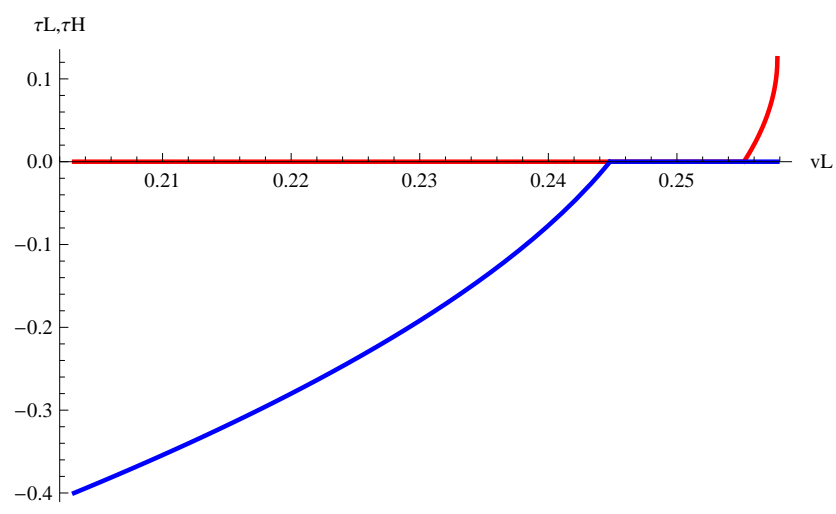

Figure 3: Marginal tax rates

The figure shows the marginal tax rates for different utility levels of the low-skilled individuals. The red curve is the marginal tax rate of the low-skilled individuals and the blue-curve is the one for the high-skilled.

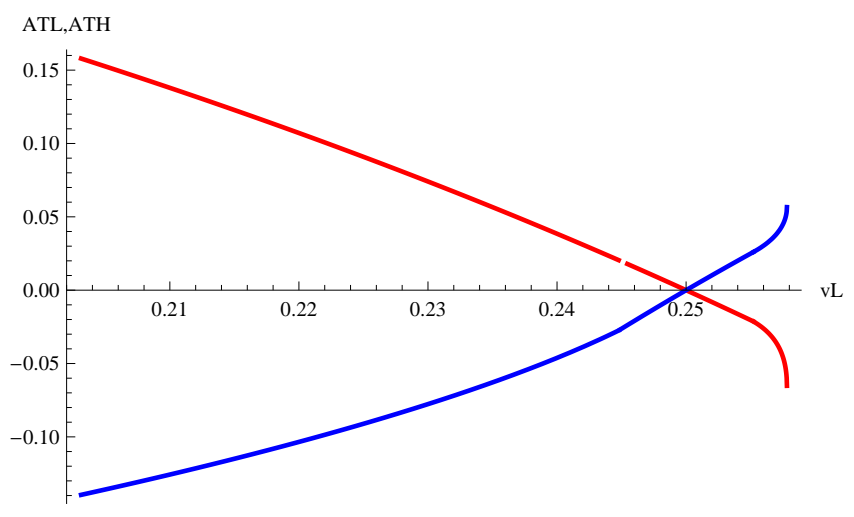

Figure 4: Average tax rates

The figure shows the average tax rates for different utility levels of the low-skilled individuals. The red curve is the average tax rate of the low-skilled individuals and the blue-curve is the one for the highskilled. 
Voting Behavior. Voters vote sincerely, i.e., a voter with skill level $w_{L}$ votes for politician $j$ if $v_{L}^{j}>v_{L}^{k}$. If $v_{L}^{j}=v_{L}^{k}$ he votes for politician $j$ if $b^{j}<b^{k}$, and votes for each politician with equal probability if $b^{j}=b^{k}$. The high-skilled voters behave in an analogous way. Thus, if both proposals deliver the same utility, a voter votes for the more competent politician 11 If the politicians are equally competent, the voter flips a coin.

Definition of Equilibrium. Politicians maximize their vote shares ${ }^{12}$ and commit to implement their electoral platforms. The set of pure strategies for politician $j$ is $S^{j}$. Our equilibrium analysis allows for mixed-strategy equilibria; that is, politicians 0 and 1 simultaneously and independently select utility promises from the sets $S^{0}$ and $S^{1}$, respectively, according to the (possibly degenerate) probability distributions $\sigma^{0}$ and $\sigma^{1}$. Voters then see the realized proposals and vote for their preferred proposal. We denote the resulting vote shares by $\Pi^{0}\left(v_{L}^{0} \mid v_{L}^{1}\right)$ and $\Pi^{1}\left(v_{L}^{1} \mid v_{L}^{0}\right)=1-\Pi^{0}\left(v_{L}^{0} \mid v_{L}^{1}\right)$.

We focus on Nash equilibria that survive the iterated elimination of weakly dominated strategies. A pair of mixed strategies $\left(\sigma^{0}, \sigma^{1}\right)$ forms an equilibrium if for every $j \in\{0,1\}$ and $k \neq j, v_{L}^{j} \in S_{+}^{j}$ with $\sigma^{j}\left(v_{L}^{j}\right)>0$,

$$
v_{L}^{j} \in \operatorname{argmax}_{\hat{v}_{L}^{j} \in S^{j}} \sum_{S_{++}^{k}} \sigma^{k}\left(v_{L}^{k}\right) \Pi\left(\hat{v}_{L}^{j} \mid v_{L}^{k}\right),
$$

where $S_{+}^{j} \subset S^{j}$ are the pure strategies of politician $j$ that survive the iterated elimination of weakly dominated strategies, and $S_{++}^{k} \subset S_{+}^{k}$ is the set of utility promises to the lowskilled that are proposed by politician $k$ with positive probability.

As will become clear below, there is always a unique Nash equilibrium that survives the iterated elimination of weakly dominated strategies. This does not preclude the existence of further Nash equilibria. However, since we are analyzing a strictly competitive game, all Nash equilibria will share essential properties. The expected payoffs of the politicians are the same in all equilibria. Moreover, the set of best-responses of politician $j$ to the equilibrium strategy of politician $k$ is the same in all equilibria. Hence, if we are able to characterize one equilibrium, we learn quite a bit about all other equilibria that might exist; see Osborne and Rubinstein (1994) for a general treatment of strictly competitive games. Finally, even if several Nash equilibria may exist, it seems natural to focus on the one that survives the iterated elimination of weakly dominated strategies.

We will be interested in a characterization of political equilibria for arbitrary quality differences. For reasons which become apparent in part B of the Appendix, our elimination exercise will, for very small quality differences, run into problems with open sets,

\footnotetext{
${ }^{11}$ The tie-breaking rule is inconsequential for the equilibrium characterization below.

${ }^{12}$ In Section 5 we discuss what results we would get if we assumed instead that politicians maximize their winning probabilities.
} 
i.e., with subsets of possible utility promises to the low-skilled in which no maximal or minimal element can be found. To be able to deal with these cases also, we will then, with some abuse of notation, interpret the strategy spaces $\tilde{S}^{0}$ and $\tilde{S}^{1}$ as arbitrarily fine discretizations of the sets of possible utility promises.

\section{Equilibrium analysis}

No Quality Difference. We start the equilibrium characterization with the symmetric case in which both politicians are equally appealing to the voters.

Proposition 1 When the politicians are of equal quality, $b^{0}=b^{1}=0$, the unique equilibrium is such that both politicians choose the maximal utility promise to the low-skilled individuals, $v_{L}^{j}=\bar{v}_{L}(0)$, for all $j \in\{0,1\}$, with probability 1 .

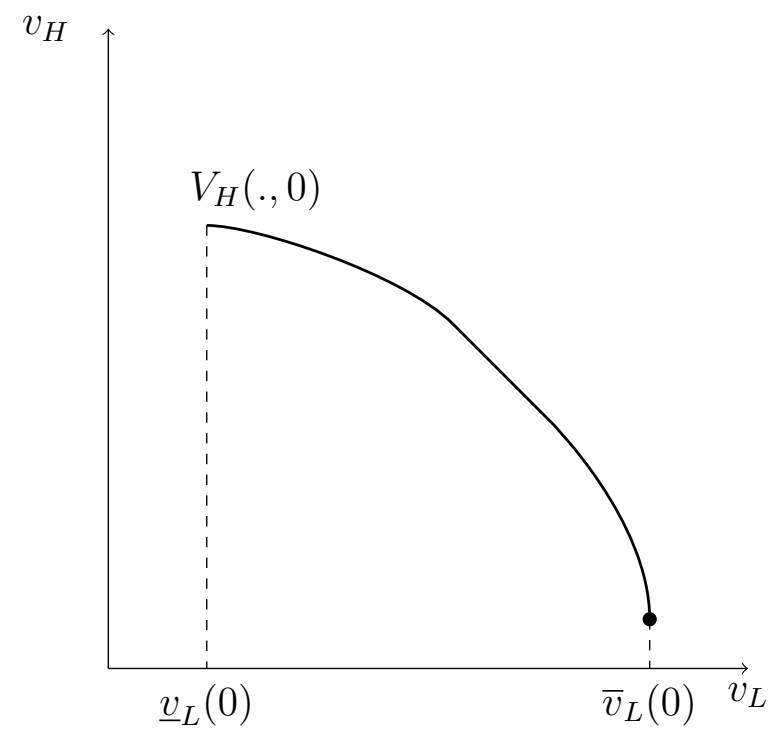

Figure 5: Second-best Pareto frontier of equally competent politicians $b^{1}=b^{0}=0$.

A sketch of the proof of Proposition 1 suffices. If both politicians are equally competent, they have access to the same set of possible utility promises, as is illustrated in Figure 5. Now, suppose that politician 1 considers to play a best response to some pure strategy $v_{L}^{0} \leq \bar{v}_{L}(0)$ of politician 0 . If he proposes some $v_{L}^{1}<v_{L}^{0}$, his vote share equals $f_{H}<\frac{1}{2}$; if he proposes $v_{L}^{1}=v_{L}^{0}$, his vote share equals $\frac{1}{2}$; and if he proposes $v_{L}^{1}>v_{L}^{0}$, which is possible only if $v_{L}^{0}<\bar{v}_{L}(0)$, his vote share equals $f_{L}>\frac{1}{2}$. Hence, politician 1 's best response is to offer more utility to the low-skilled individuals than politician 0 .

Since our choice of $v_{L}^{0}$ was arbitrary, this reasoning implies (i) that playing $v_{L}^{1}=\bar{v}_{L}(0)$ is a best response for politician 1, whatever the proposal of politician 0 is, and (ii) that any 
other proposal is weakly dominated: if politician 1 chose some $v_{L}^{1}<\bar{v}_{L}(0)$ with positive probability, he could increase his expected payoff against some strategies of politician 0 , namely against those that involve proposals $v_{L}^{0} \geq v_{L}^{1}$ with positive probability.

Thus, if politicians do not differ in terms of quality, they both choose policy so as to maximize the well-being of the larger group, the low-skilled individuals, at the expense of the well-being of the smaller group, the high-skilled individuals 13

The outcome of political competition is different from the outcome that would be obtained if a utilitarian social planner chose the optimal policy. A utilitarian planner chooses $v_{L}$ in order to maximize $f_{L} v_{L}+f_{H} V_{H}\left(v_{L}, 0\right)$. The solution is the point on the frontier that has slope $\frac{f_{L}}{f_{H}}$. Political competition, by contrast, selects the outcome where the slope of the frontier is equal to infinity. This is the outcome that would be chosen by a Rawlsian social planner who cares only for the low-skilled, i.e., a planner who maximizes $v_{L}$, subject to the constraint that $v_{L} \in\left[\underline{v}_{L}(0), \bar{v}_{L}(0)\right]$.

Large Quality Differences. We are now moving to the version of our model in which the two politicians differ in quality, so that $b^{1}>b^{0}=0$. Our equilibrium characterization will depend on the size of the quality difference. We first consider the case of a large quality difference between politician 1 and politician 0 , which arises when politician 0 has a set of pure strategies that guarantee him a vote share of 1 , whatever the strategy played by politician 1. Graphically, such a case is illustrated by Figure 6. More formally, we say that the quality difference is large if $b^{1}$ is such that

$$
\underline{h}:=h\left(\underline{v}_{L}^{1}\left(b^{1}\right)\right) \geq \bar{v}_{L}^{1}\left(b^{1}\right)
$$

where, for an arbitrary utility promise $v_{L}^{1}$ of politician $1, h\left(v_{L}^{1}\right)$ is implicitly defined by the equation

$$
V_{H}\left(v_{L}^{1}, b^{1}\right)=V_{H}\left(h\left(v_{L}^{1}\right), 0\right) .
$$

Hence, given a utility promise to low-skilled individuals by politician $1, v_{L}^{1}$, and a quality difference $b^{1}, h\left(v_{L}^{1}\right)$ is the utility promise to the low-skilled by politician 0 which is such that the high-skilled are indifferent between the two proposals.

In case of a large quality difference, politician 0 can win a vote share of 1 by making a utility promise to the low-skilled that belongs to $\left[\bar{v}_{L}^{1}\left(b^{1}\right), \underline{h}\right]$.

A comparison between the case of a large quality difference and the case with no quality difference at all, reveals the following: the equilibrium policy if there is no quality difference is extreme in the sense that the utility of the low-skilled is maximized with no

\footnotetext{
${ }^{13}$ Given that, in our simple setup, the larger group also contains the median skill level, we can interpret this result as a version of the median voter theorem.
} 
concern for the utility of the high-skilled. Put differently, the equilibrium policy is the one that would be chosen by a social planner who seeks to maximize a Rawlsian welfare function. By contrast, if there is a large quality difference, then the equilibrium policy is moderate in the sense that the utility of the high-skilled is bounded away from their worst outcome.

This moderation is obtained because the good politician needs to make sure that the bad politician can neither make a more attractive offer to the low-skilled, nor a more attractive offer to the high-skilled. To prevent such a "market entry" by the competitor, the good politician's proposals have to be sufficiently attractive both to the low-skilled and to the high-skilled. This rules out extreme proposals. These considerations are summarized in the following Proposition.

Proposition 2 When the quality difference is large, so that $h\left(\underline{v}_{L}^{1}\left(b^{1}\right)\right) \geq \bar{v}_{L}^{1}\left(b^{1}\right)$, the good politician wins with probability 1 and the equilibrium policy is bounded away from the Rawlsian outcome, i.e., $v_{L}^{0}<\bar{v}_{L}(0)$.

Intermediate Quality Differences. With an intermediate quality difference, the good politician no longer possesses a pure strategy that guarantees him a vote share of 1 . Whatever he proposes, the bad politician can find a proposal that is more attractive to at least one group of voters. Formally, we define the case of an intermediate quality difference by the properties $\bar{v}_{L}^{1}>\underline{h}$, and $\underline{h} \geq \bar{h}$, where

$$
\bar{h}:=h^{-1}\left(\bar{v}_{L}^{1}\right)
$$

A situation with an intermediate quality difference is depicted in Figure 7. As a first step in the equilibrium characterization, the following Lemma narrows down the set of proposals that survive the iterated elimination of weakly dominated strategies. It shows that, in equilibrium, the set of possible proposals by the good candidate are more moderate than those of the bad candidate. Intuitively, the good politician uses his competitive advantage in order to be appealing to both groups of voters. The bad politician, by contrast, makes extreme offers to increase his chance of getting at least one group of voters. Specifically, the bad politician either makes the most attractive offer to the low-skilled, or the most attractive offer to the high-skilled; i.e., the Rawlsian outcome, with no concern for the high-skilled, or the Anti-Rawlsian outcome, with no concern for the low-skilled.

Lemma 1 Suppose that there is an intermediate quality difference between politicians. Then, the support of politician 1 's equilibrium strategy is contained in $\left\{\underline{v}_{L}^{1}, \bar{v}_{L}^{1}\right\}$, and the support of politician 0 's equilibrium strategy is contained in $\left\{\underline{h}, \bar{v}_{L}^{1}\right\}$. 
Proof First round of elimination. Consider Figure 7. As a first step, we observe that politician 0 will not make offers strictly smaller than $\underline{h}$. Any such offer would imply that he gains the votes of all high-skilled voters. However, he would still gain all high-skilled voters if he offers $\underline{h}$. Moreover, $\underline{h}$ gains more low-skilled voters. It gains strictly more low-skilled voters, whenever politician 1 chooses $v_{L}^{1}<\underline{h}$ with positive probability. A symmetric argument implies that politician 0 will not make offers strictly larger than $\bar{v}_{L}^{1}$.

Second round of elimination. We now take as given that politician 0 makes only offers from the segment of his frontier that lie between $\underline{h}$ and $\bar{v}_{L}^{1}$.

(i) Politician 1 will not make offers to the low-skilled that belong to the interval $[\bar{h}, \underline{h}]$. With any such offer his vote share would be equal to 0 . (ii) Now consider the interval ]$\underline{h}, \bar{v}_{L}^{1}[$. Given politician 0's behavior, in this range politician 1 does not get votes from the high-skilled individuals. By offering $\bar{v}_{L}^{1}$ he still does not get high-skilled voters, but he weakly increases the chance of getting the low-skilled voters. This implies that politician 1 will not make offers from the interval $] \underline{h}, \bar{v}_{L}^{1}[$. (iii) A symmetric argument implies that he will not make offers from the interval $] \underline{v}_{L}^{1}, \bar{h}[$.

Third round of elimination. We now take as given that politician 1 makes only offers in $\left\{\underline{v}_{L}^{1}, \bar{v}_{L}^{1}\right\}$. We show that politician 0 is not making offers in $] \underline{h}, \bar{v}_{L}^{1}[$. Suppose, on the contrary, that he would make an offer from this interval, and consider a deviation to $\bar{v}_{L}^{1}$. Conditional on politician 1 playing $\underline{v}_{L}^{1}$, this does not affect politician 0's vote share: he still gains the votes of the low-skilled individuals and loses the votes of the high-skilled individuals. Conditional on politician 1 playing $\bar{v}_{L}^{1}$, he will now win the votes of all voters, and he will not lose the high-skilled voters.

The Lemma implies that we can characterize the equilibrium proposals by looking at the standard normal form game in Table 1. This is a strictly competitive game, so that only a mixed-strategy equilibrium exists. Using standard arguments, we can solve for the unique mixed-strategy equilibrium. Proposition 3 summarizes the results.

Proposition 3 When the quality advantage is intermediate there is a unique equilibrium which is such that politician 1 plays $\underline{v}_{L}^{1}$ with probability $f_{L}$ and $\bar{v}_{L}^{1}$ with probability $f_{H}$ and politician 0 plays $\underline{h}$ with probability $f_{H}$ and $\bar{v}_{L}^{1}$ with probability $f_{L}$.

The logic of the mixed-strategy equilibrium is as follows: the good politician tries to get the votes of the high-skilled without giving the bad politician an opportunity to attract the low-skilled voters. This leads him to offer $\bar{v}_{L}^{1}$ to the low-skilled, i.e., the maximal utility that the bad politician could possibly offer to the low-skilled. Now, given that the good politician is making this proposal, the bad politician has to make a much 


\begin{tabular}{c|ccc|ccc} 
Politician 0 \Politician 1 & \multicolumn{3}{|c}{$\underline{v}_{L}^{1}$} & & \multicolumn{3}{|c}{$\bar{v}_{L}^{1}$} \\
\hline$\underline{h}$ & 1 &, & 0 & $f_{H}$ &, & $f_{L}$ \\
& & & & & & \\
$\bar{v}_{L}^{1}$ & $f_{L}$ &, & $f_{H}$ & 1 &, & 0 \\
\hline
\end{tabular}

Table 1: The normal form game in case of intermediate quality differences.

more attractive offer to the high-skilled to get at least their votes. The probability of getting their votes is maximized with the proposal $\underline{v}_{L}^{1}$. However, the story does not end here: if the bad politician tries to distinguish himself in this manner, the good politician has an incentive to make the offer $\underline{h}$ which is equally attractive to the high-skilled and still more attractive to the low-skilled than the competitor's offer. The good politician would then gain a vote share of 1 . Now, given this behavior, the bad politician has the opportunity to deviate and to make a more attractive offer to the low-skilled, which would make him win a majority of votes.

The mixed-strategy equilibrium is shaped by these two forces: the good politician mainly wants to prevent the entry of the bad politician in the market for the low-skilled. He chooses the entry-deterring policy with probability $f_{L}>\frac{1}{2}$. Note that the probability that he protects his share of the low-skilled individuals' votes is exactly equal to the size of this group $f_{L}$. On the other hand, he cannot completely resist the temptation to go occasionally also for the votes of the high-skilled. The intensity of this temptation is equal to the size of the minority $f_{H}$. Given that the good politician, most of the time, protects his share of the low-skilled, the high-skilled politician, most of the time (also, with probability $f_{L}$ ), protects his share of the high-skilled. Occasionally, however, he tries to take advantage of his competitor's temptation and to steal the votes of the low-skilled. Thus, in equilibrium, the bad politician caters more to the high-skilled and the good politician caters more to the low-skilled.

Such a moderation was already observed under the assumption of a large quality difference. A difference between the case of a large and an intermediate quality difference lies in the observation, that, with a large quality difference, the bad politician does not gain any votes in equilibrium. Hence, moderation is driven by potential competition outof-equilibrium. With an intermediate quality difference, by contrast, the bad politician gains votes in equilibrium.

We will, by induction, provide an equilibrium characterization that covers all subcases in which the quality difference is smaller than in the situations discussed so far. In part B of the Appendix, we will spell out the details of the proof. The general lesson is that, as we decrease the quality difference, for each politician, more proposals survive the iterated 
elimination of weakly dominated strategies. Moreover, whatever the quality difference, the good politician 0 draws his proposals from a bounded segment of his frontier. The smallest proposal that is made with positive probability is $\underline{h}$ and the largest one is $\bar{v}_{L}^{1}$. Politician 1 makes the smallest proposal on his frontier, $\underline{v}_{L}^{1}$, and the largest one, $\bar{v}_{L}^{1}$, with positive probability. Moreover, the bad politician randomizes in such a way that proposals that are more attractive to the high-skilled have more probability mass, whereas the good politician puts more mass on proposals that are more attractive to the low-skilled. Hence, the proposition generalizes the observations that were made previously for the special cases of an intermediate quality difference. In the following, we will illustrate all these properties by moving one step further and considering the case of a small quality difference.

Small quality differences. We define a small quality difference by two properties: first, it is not intermediate which implies that $\bar{h} \geq \underline{h}$; second, it satisfies $\underline{h}^{2}>\bar{h}^{2}$, where we define,

$$
\underline{h}^{2}:=h(\underline{h}) \text { and } \bar{h}^{2}:=h^{-1}(\bar{h}),
$$

see Figure 8 .

Lemma 2 Consider the case of a small quality difference and suppose that $\bar{h}^{2} \leq \underline{h}$, see Figure 8. The support of politician 1's equilibrium strategy is contained in $\left\{\underline{v}_{L}^{1}, M^{1}, \bar{v}_{L}^{1}\right\}$, where $\left.M^{1}:=\tilde{S}^{1} \cap\right] \underline{h}, \bar{h}[$. The support of politician 0 's equilibrium strategy is contained in $\left\{\underline{h}, M^{0}, \bar{v}_{L}^{1}\right\}$, where $M^{0}:=\tilde{S}^{0} \cap\left[\bar{h}, \underline{h}^{2}\right]$.

Lemma 2 illustrates the following more general observations: first, as we decrease the quality difference between the two politicians - i.e., so that the Pareto-frontier of politician 1 gets closer to the Pareto-frontier of politician 0 - the more policies survive the iterated elimination of weakly dominated strategies. Now each politician randomizes effectively between three actions, whereas in the case of an intermediate quality difference each politician is randomizing between two actions 14

This increase in the support of equilibrium policies stems from the fact that the bad politician can gain the support of one group of voters even with a moderate proposal. To see this more formally, suppose that politician 0 would, as in the case of an intermediate quality difference, only make proposals $\underline{h}$ and $\bar{v}_{L}^{1}$ with positive probability. Then, from Table 2, politician 1 can make moderate proposals in $M^{1}$ that are always a best response, so that he will no longer play $\underline{v}_{L}^{1}$ and $\bar{v}_{L}^{1}$. But then, politician 0 would want

\footnotetext{
${ }^{14}$ The "actions" labeled $M^{0}$ and $M^{1}$ each represent a large number of proposals, which are, however, payoff-equivalent in equilibrium.
} 
to make moderate proposals also, those in $M^{0}$, to win with a vote share of 1 . Hence, the equilibrium that was obtained with an intermediate quality difference, is no longer an equilibrium if the quality difference is made smaller. Now, each politician randomizes between three actions in equilibrium.

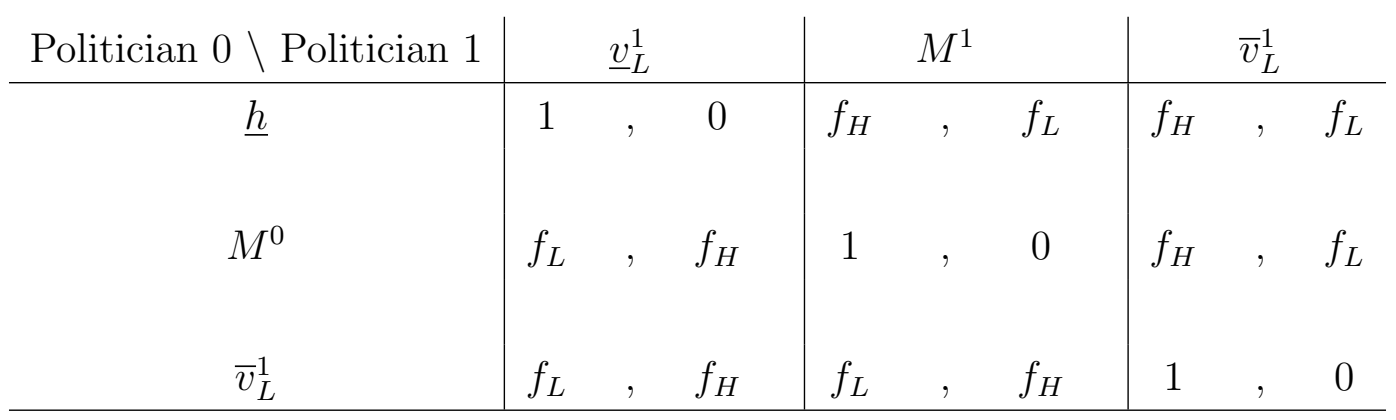

Table 2: The normal form game in case of a small quality difference.

Proposition 4 Consider the case of a small quality difference and suppose that $\bar{h}^{2} \leq \underline{h}$. Then, the unique equilibrium is as follows:

i) Politician 1 plays $\underline{v}_{L}^{1}$ with probability $p_{0}^{1}$, a proposal in $M^{1}$ with probability $p_{1}^{1}=\frac{f_{H}}{f_{L}} p_{0}^{1}$ and $\bar{v}_{L}^{1}$ with probability $p_{2}^{1}=\left(\frac{f_{H}}{f_{L}}\right)^{2} p_{0}^{1}$, where $p_{0}^{1}=\frac{1}{1+\frac{f_{H}}{f_{L}}+\left(\frac{f_{H}}{f_{L}}\right)^{2}}$.

ii) Politician 0 plays $\underline{h}$ with probability $q_{0}^{0}$, a proposal in $M^{0}$ with probability $q_{1}^{0}=\frac{f_{L}}{f_{H}} q_{0}^{0}$ and $\bar{v}_{L}^{1}$ with probability $q_{2}^{0}=\left(\frac{f_{L}}{f_{H}}\right)^{2} q_{0}^{0}$, where $q_{0}^{0}=\frac{1}{1+\frac{f_{L}}{f_{H}}+\left(\frac{f_{L}}{f_{H}}\right)^{2}}$.

Proof The proof follows from a characterization of the mixed strategy equilibria of the normal form game in Table 2, This is a special case of Proposition 5 below.

Proposition 4 shows that, with a small quality difference, the bad politician makes moderate policy proposals with positive probability and no longer randomizes exclusively between the extreme outcomes $\underline{v}_{L}^{1}$ and $\bar{v}_{L}^{1}$. Otherwise, we obtain similar conclusions as for the case of an intermediate quality difference: the equilibrium strategy of the good politician 0 has more probability mass on proposals that are more attractive to the low-skilled, whereas the bad politician's probability distribution caters more to the high-skilled. More formally, for two proposals $v_{L}^{0}$ and $\hat{v}_{L}^{0}$ which are made by politician 0 with positive probability, $v_{L}^{0}>\hat{v}_{L}^{0}$ implies that $v_{L}^{0}$ is played with a larger probability than $\hat{v}_{L}^{0}$. By contrast, for politician 1 we have that $v_{L}^{1}>\hat{v}_{L}^{1}$ implies that $v_{L}^{1}$ is played with a smaller probability than $\hat{v}_{L}^{1}$.

Smaller quality differences. In part B of the Appendix, we show that there is a natural order in which the quality difference can be decreased in a sequence of steps, so as 
to obtain a complete equilibrium characterization by induction. Every step implies that, for each of the two politicians, one additional proposal survives the iterated elimination of weakly dominated strategies. The normal form game in Table 3 illustrates the outcome of the elimination exercise for an arbitrarily small quality difference. It presents, for each politician, the $N$ proposals that survive the iterated elimination of weakly dominated strategies. These proposals are ordered, so that a larger number is associated with a proposal that is more attractive to the low-skilled. The following proposition, which is proven in the Appendix, shows that any such proposal is played with positive probability in equilibrium. Moreover, the bad politician randomizes in such a way that proposals that are more attractive to the high-skilled have more probability mass, whereas the good politician puts more mass on proposals that are more attractive to the low-skilled. Hence, the proposition generalizes the observations that were made previously for the special cases of intermediate and small quality differences.

\begin{tabular}{c|cccccccccc} 
Pol $0 \backslash$ Pol 1 & $v_{L 0}^{1}$ & $v_{L 1}^{1}$ & $v_{L 2}^{1}$ & $v_{L 3}^{1}$ & $v_{L 4}^{1}$ & $v_{L 5}^{1}$ & $\ldots$ & $v_{L N-2}^{1}$ & $v_{L N-1}^{1}$ & $v_{L N}^{1}$ \\
\hline$v_{L 0}^{0}$ & 1,0 & $f_{H}, f_{L}$ & $f_{H}, f_{L}$ & $\ldots$ & $\ldots$ & $\ldots$ & $\ldots$ & $f_{H}, f_{L}$ & $f_{H}, f_{L}$ & $f_{H}, f_{L}$ \\
$v_{L 1}^{0}$ & $f_{L}, f_{H}$ & 1,0 & $f_{H}, f_{L}$ & $\ldots$ & $\ldots$ & $\ldots$ & $\ldots$ & $f_{H}, f_{L}$ & $f_{H}, f_{L}$ & $f_{H}, f_{L}$ \\
$v_{L 2}^{0}$ & $f_{L}, f_{H}$ & $f_{L}, f_{H}$ & 1,0 & $f_{H}, f_{L}$ & $\ldots$ & $\ldots$ & $\ldots$ & $f_{H}, f_{L}$ & $f_{H}, f_{L}$ & $f_{H}, f_{L}$ \\
$v_{L 3}^{0}$ & $f_{L}, f_{H}$ & $f_{L}, f_{H}$ & $f_{L}, f_{H}$ & 1,0 & $f_{H}, f_{L}$ & $\ldots$ & $\ldots$ & $f_{H}, f_{L}$ & $f_{H}, f_{L}$ & $f_{H}, f_{L}$ \\
$v_{L 4}^{0}$ & $f_{L}, f_{H}$ & $f_{L}, f_{H}$ & $f_{L}, f_{H}$ & $f_{L}, f_{H}$ & 1,0 & $f_{H}, f_{L}$ & $\ldots$ & $f_{H}, f_{L}$ & $f_{H}, f_{L}$ & $f_{H}, f_{L}$ \\
$v_{L 5}^{0}$ & $f_{L}, f_{H}$ & $f_{L}, f_{H}$ & $f_{L}, f_{H}$ & $f_{L}, f_{H}$ & $f_{L}, f_{H}$ & 1,0 & $\ddots$ & $f_{H}, f_{L}$ & $f_{H}, f_{L}$ & $f_{H}, f_{L}$ \\
$\vdots$ & $\vdots$ & $\vdots$ & $\vdots$ & $\vdots$ & $\vdots$ & $\ddots$ & $\ddots$ & $\ddots$ & $\vdots$ & $\vdots$ \\
$v_{L N-2}^{0}$ & $f_{L}, f_{H}$ & $f_{L}, f_{H}$ & $f_{L}, f_{H}$ & $\ldots$ & $\ldots$ & $\ldots$ & $f_{L}, f_{H}$ & 1,0 & $f_{H}, f_{L}$ & $f_{H}, f_{L}$ \\
$v_{L N-1}^{0}$ & $f_{L}, f_{H}$ & $f_{L}, f_{H}$ & $f_{L}, f_{H}$ & $\ldots$ & $\ldots$ & $\ldots$ & $f_{L}, f_{H}$ & $f_{L}, f_{H}$ & 1,0 & $f_{H}, f_{L}$ \\
$v_{L N}^{0}$ & $f_{L}, f_{H}$ & $f_{L}, f_{H}$ & $f_{L}, f_{H}$ & $\ldots$ & $\ldots$ & $\ldots$ & $f_{L}, f_{H}$ & $f_{L}, f_{H}$ & $f_{L}, f_{H}$ & 1,0 \\
\hline \multicolumn{7}{c}{ where $v_{L 0}^{0}=\underline{h}, v_{L N}^{0}=\bar{v}_{L}^{1}, v_{L 0}^{1}=\underline{v}_{L}^{1}$, and $v_{L N}^{1}=\bar{v}_{L}^{1}}$. & & &
\end{tabular}

Table 3: The normal form game in case of very small quality differences.

Proposition 5 Consider the normal form game in Table 3 . This game has a unique mixed strategy Nash equilibrium with the following properties:

i) Politician 1 plays all actions with positive probability. More specifically, he chooses action $v_{L k}^{1}$ with probability $p_{k}^{1}=\left(\frac{f_{H}}{f_{L}}\right)^{k} p_{0}^{1}$, where $p_{0}^{1}=\frac{1}{\sum_{k=0}^{N}\left(\frac{f_{H}}{f_{L}}\right)^{k}}$.

ii) Politician 0 plays all actions with positive probability. More specifically, he chooses action $v_{L k}^{0}$ with probability $q_{k}^{0}=\left(\frac{f_{L}}{f_{H}}\right)^{k} q_{0}^{0}$, where $q_{0}^{0}=\frac{1}{\sum_{k=0}^{N}\left(\frac{f_{L}}{f_{H}}\right)^{k}}$.

In the following, we consider the limit case as we let the quality difference between the two politicians vanish. As a corollary of Proposition 5, we obtain the following characterization of the political equilibrium that is obtained as the quality difference between the two politicians gets arbitrarily small. 
Corollary 1 Consider the normal form game in Table 3. As the quality difference goes to zero, the number $N$ of actions goes to infinity and

i) the probability $q_{N}^{0}$ that politician 0 makes the largest proposal $v_{L N}^{0}=\bar{v}_{L}^{1}$ converges to 1 ;

ii) the probability $p_{0}^{1}$ that politician 1 makes the smallest proposal $v_{L 0}^{1}=\underline{v}_{L}^{1}$ converges to $1-\frac{f_{H}}{f_{L}}$. The probability that he makes the largest proposal $v_{L N}^{1}=\bar{v}_{L}^{1}$ converges to 0 .

Corollary 1 states that, as the quality difference vanishes, the probability that politician 0 chooses the proposal on his frontier that gives maximal utility to the low-skilled converges to one $\sqrt{15}$ The most likely proposal by politician 1 , by contrast, is the one that gives maximal utility to the high-skilled. The corresponding limit probability is smaller than 1 . Hence, politician 1 also makes some moderate proposals with positive probability. By contrast, the probability of proposals close to the one giving maximal utility to the low-skilled, $\bar{v}_{L}^{1}$, is going to zero.

The surprising insight here is that the limit case, which is obtained as the quality difference vanishes, behaves differently from the case with no quality difference. The latter gives rise to a unique equilibrium in which both politicians make the proposal that is most attractive to the larger group, the low-skilled. Our result shows that an arbitrarily small quality difference suffices to break this asymmetry. With a quality difference arbitrarily close to, but different from, zero, the bad politician 1 "specializes" on proposals that are more attractive to the high-skilled, and the good politician 0 "specializes" on those that are more attractive to the low-skilled. Consequently, the outcome of Downsian competition between opportunistic parties looks as if proposals were made by two ideological parties, a party catering to the rich and a party catering to the poor.

Tax rates revisited. Using Proposition 5 and Corollary 1, we can now comment on what implications our equilibrium analysis has for marginal tax rates. The bad politician makes proposals that are more attractive to the rich with larger probability. In combination with the implications for tax rates this implies that proposals which correspond to lower marginal tax rates are made with a larger probability. By contrast, the good politician proposes higher marginal tax rates with a higher probability.

The limit case, as the quality difference gets arbitrarily small, has the following implications for marginal income tax rates: the good politician proposes maximal marginal tax rates with probability 1 . This involves a positive marginal tax rate on low-skilled labor and a zero marginal tax rate on high-skilled labor. The most likely proposal of the bad

\footnotetext{
${ }^{15}$ Note that, as the quality difference disappears, we also have that $\bar{v}_{L}^{1}$ converges to $\bar{v}_{L}^{0}$.
} 
politician involves minimal marginal tax rates, hence a zero marginal-tax on low-skilled labor and a negative marginal tax rate on high-skilled labor.

\section{$5 \quad$ Political systems and political failures}

In this section, we will first explain how the results of our analysis change if politicians maximize their probability of winning, as opposed to their vote share. The assumption that politicians maximize their vote shares more closely portrays a political system with proportional representation, so that larger vote shares translate into additional seats in parliament (see, e.g., Persson and Tabellini, 2000; Lizzeri and Persico, 2001; Sahuguet and Persico, 2006). By contrast, the assumption that politicians maximize their winning probabilities fits better in a winner-take-all system. Secondly, we compare the two equilibria from a welfare perspective.

\subsection{Equilibrium in a winner-take-all system}

We now assume that politicians care only about their probability of winning an election. Formally, we assume that a politician's payoff, from an ex post perspective, is equal to 1

if his vote share is strictly larger than $\frac{1}{2}$, equal to $\frac{1}{2}$ if his vote share is equal to $\frac{1}{2}$, and zero otherwise.

The characterization of equilibria under this assumption is straightforward: if there is no quality difference between the politicians, then the equilibrium is the same as under the assumption of vote-share maximization, i.e., both politicians propose the tax policy that is most attractive to the majority of low-skilled individuals.

If there is a quality difference, then, for the good politician, all proposals $v_{L}^{0}$ larger than the "limit tax policy" $\bar{v}_{L}^{1}$, guarantee a vote share of $f_{L}>\frac{1}{2}$, and hence a payoff of 1 , whatever the proposal of the bad politician. These proposals are therefore payoffequivalent for the good politician, whereas all proposals $v_{L}^{0}<\bar{v}_{L}^{1}$ are strictly dominated. Given that the good politician can make sure to get a majority, any behavior of the bad politician is a best-response. He is getting a payoff of 0 , no matter what he proposes. Vote shares are therefore undetermined. The good politician may get a vote share of 1 or a vote share of $f_{L}$ in equilibrium. The bad politician gets a vote share of 0 , or a vote share of $f_{H}$.

What all equilibria in the winner-take-all system have in common is the following: the good politicians wins, implying that the equilibrium policy lies on the superior Paretofrontier. The well-being of the low-skilled in equilibrium is bounded from below by $\bar{v}_{L}^{1}$, the well-being of the high-skilled is bounded from above by $V_{H}\left(\bar{v}_{L}^{1}, 0\right)$. Finally, as we 
make the quality difference smaller and smaller, $\bar{v}_{L}^{1}$ converges to $\bar{v}_{L}^{0}$, i.e., the equilibrium policy converges to the one that would result if there was no quality difference at all.

We can now compare the tax rates implied by our equilibrium analysis for the two political systems. When the politicians differ in term of quality, political equilibria under majoritarian system have higher expected tax rates than the one under proportional representation. Redistribution towards the larger group, i.e., the low-skilled agents, is then exacerbated under majoritarian system. This confirms previous findings showing that majoritarian systems are associated with larger government and favor targeted redistribution towards a narrow constituency compared to proportional systems (see Persson and Tabellini, 2000; Lizzeri and Persico, 2001).

\subsection{A welfare comparison}

A comparison between equilibria under vote-share maximization or proportional representation, on the one hand, and under a winner-take-all system in which politicians maximize the probability of winning, on the other, yields the following observation: voteshare maximization gives rise to the possibility of political failures in the sense of Besley and Coate (1998). Such political failures are avoided with politicians who maximize winning probabilities. The reasoning is as follows: a political failure occurs if an economy's set of feasible policies contains a policy that Pareto-dominates the one that is chosen in the political equilibrium. Clearly, such a failure occurs whenever the bad politician wins an election because this implies that the equilibrium policy lies on an inferior frontier, i.e., one that involves excessive government consumption $b^{1}>b^{0}$. Since a victory of the bad politician is possible only under the assumption of vote-share maximization, but not if politicians maximize winning probabilities, we can conclude that, in our model, proportional representation gives rise to political failures that are avoided in a winner-take-all system. As political failures are associated with larger government consumption, i.e. rent for the bad politician $b^{1}$, our result confirms previous findings that majoritarian election reduces rents for politicians (see Persson and Tabellini, 2000).

At the same time, however, the equilibrium involving a political failure in the sense of Besley and Coate (1998) may not be Pareto-dominated by the equilibrium that avoids a political failure. To see this, it is instructive to look at the equilibrium with voteshare-maximizing politicians under the assumption of an intermediate quality difference. In this case, the bad politician wins with a probability of $f_{H}^{2}$ and this event gives rise to a political failure. With probability $1-f_{H}^{2}$, the good politician wins. Moreover, if the good politician wins, he wins with a proposal $v_{L}^{0} \leq \bar{v}_{L}^{1}$ and the event $v_{L}^{0}<\bar{v}_{L}^{1}$ has positive probability (which equals $f_{H} f_{L}$ in case of an intermediate quality difference). In a winner-take-all system, by contrast, the good politician wins with probability 1 and 
only makes proposals $v_{L}^{0} \geq \bar{v}_{L}^{1}$. Hence, conditional on a victory of the good politician, the minority of high-skilled individuals is better off under proportional representation, whereas the majority of low-skilled individuals is better off in a winner-take-all system. Now, if the probability that the bad politician wins is sufficiently small, i.e., if the minority is small, so that $f_{H}^{2}$ is close to 0 , then it is clear that the minority prefers proportional representation, even if the small probability of a political failure is taken into account.

At first glance, these results may seem paradoxical: the equilibrium involving Paretodominated policies is not Pareto-dominated by the equilibrium avoiding Pareto-dominated policies. The reason is that, under proportional representation, the good politician, who is most likely to win, chooses policies that are more attractive to the high-skilled than those that would be chosen in a winner-take-all system. However, this improvement for the minority of high-skilled individuals is possible only if there is small probability that an inefficient policy is chosen in equilibrium.

\section{Concluding remarks}

This paper has studied Downsian political competition in a simple Mirrleesian model of income taxation. Allowing for quality differences among the two competing politicians, we found, as a main result, that the bad politician's proposals are designed in order to attract the votes of the rich, whereas the good politician tries to get the votes of the poor. The limit case that is obtained as the quality difference vanishes has the following most likely outcome: the good politician's proposal is the one that would be made by a Rawlsian social planner, with no concern for the well-being of the rich, and the bad politician's proposal is the one that would be made by an Anti-Rawlsian planner, with no concern for the poor.

We also provided a welfare comparison of political equilibria under proportional representation and a winner-take-all system. If there is a quality difference, the outcomes in the two systems differ. The bad politician may win under proportional representation which gives rise to a political failure in the sense of Besley and Coate (1998). However, this does not imply that a winner-take-all system Pareto-dominates a system with proportional representation. The minority of high-skilled agents may well be better off under proportional representation.

The model was made tractable by the assumption that the economy consists only of two groups, a large group of low-skilled or poor agents, and a small group of high-skilled or rich agents. Our approach was based on the Pareto-frontier in the Mirrleesian model of income taxation, i.e., on a characterization of possible utility promises to high- and low-skilled individuals, respectively. A similar approach could conceivably be used in 
more general models.

\section{References}

Acemoglu, D., M. Golosov and A. Tsyvinski. 2008. "Political Economy of Mechanisms." Econometrica 76:619-641.

Acemoglu, D., M. Golosov and A. Tsyvinski. 2010. "Dynamic Mirrlees Taxation under Political Economy Constraints." Review of Economic Studies 77:841-881.

Adams, J. 1999. "Policy divergence in multicandidate probabilitic spatial voting." Public Choice 100(1):103-122.

Ansolabehere, S. and J. M. Snyder. 2000. "Valence politics and equilibrium in spatial election models." Public Choice 103:327-336.

Aragones, E. and R. Palfrey. 2002. "Mixed Equilibrium in a Downsian Model with a Favored Candidate." Journal of Economic Theory 103:131-161.

Baron, D.P. and J.A. Ferejohn. 1989. "Bargaining in Legislatures." American Political Science Review 83:1181-1206.

Barro, R. 1973. "The Control of Politicians: An economic model." Public Choice 14:1942.

Battaglini, M. and S. Coate. 2008. "A Dynamic Theory of Public Spending, Taxation and Debt." American Economic Review 98:201-236.

Besley, T. 2005. "Political Selection." Journal of Economic Perspectives 19(3):43-60.

Besley, T. 2006. Principled Agents? The Political Economy of Good Government. Oxford University Press.

Besley, T. and S. Coate. 1997. "A Model of Representative Democracy." Quarterly Journal of Economics 112:85-114.

Besley, T. and S. Coate. 1998. "Sources of Inefficiency in a Representative Democracy: A Dynamic Analysis." American Economic Review 88:139-156.

Bierbrauer, F.J. and P.C. Boyer. 2010. "The Pareto-Frontier in a simple Mirrlees model of income taxation." Preprints of the Max Planck Institute for Research on Collective Goods, Bonn 2010/16. 
Bohn, H. and C. Stuart. 2011. "Let's Pay Lower Taxes: Revenue Extraction by Median Voters." Working Paper.

Brewer, M., E. Saez and A. Shephard. 2010. Means Testing and Tax Rates on Earnings. Institute for Fiscal Studies, Oxford University Press.

Carbonell-Nicolau, O. and E. A. Ok. 2007. "Voting over income taxation." Journal of Economic Theory 134:249-286.

Casamatta, G., H. Cremer and P. De Donder. 2010. "Repeated electoral competition over nonlinear income tax schedules." Social Choice and Welfare 35:535-574.

Crutzen, B. and N. Sahuguet. 2009. "Redistributive politics with distortionary taxation." Journal of Economic Theory 144:264-279.

De Donder, P. and J. Hindriks. 2003. "The Politics of Progressive Income Taxation with Incentive Effects." Journal of Public Economics 87:2491-2505.

Downs, A. 1957. An Economic Theory of Democracy. New York, Harper and Row.

Fahri, E. and I. Werning. 2008. "The Political Economy of Non-Linear Capital Taxation." Mimeo, MIT.

Ferejohn, J. 1986. "Incumbent Performance and electoral control." Public Choice 50:5-25.

Galasso, V. and T. Nannicini. 2011. "Competing on Good Politicians." American Political Science Review 105:79-99.

Groseclose, T. 2001. "A Model of Candidate Location When One Candidate Has a Valence Advantage." American Journal of Political Science 45(4):862-886.

Guesnerie, R. 1995. A Contribution to the Pure Theory of Taxation. Cambridge University Press.

Krasa, S. and M. Polborn. 2009. "A political-economy model of taxation and government expenditures with differentiated candidates." Working Paper .

Laslier, J.-F. and N. Picard. 2002. "Distributive Politics and electoral competition." Journal of Economic Theory 103:106-130.

Lijphart, A. 1999. Patterns of Democracy: Government Forms and Performance in Thirty-Six Countries. New Haven: Yale University Press.

Lindbeck, A. and J. Weibull. 1987. "Balanced-budget Redistribution as the Outcome of Political Competition." Public Choice 52:273297. 
Lizzeri, A. and N. Persico. 2001. "The Provision of Public Goods under Alternative Electoral Incentives." American Economic Review 91(1):225-239.

Martimort, D. 2001. "Optimal Taxation and Strategic Budget Deficit under Political Regime Switching." Review of Economic Studies 68:573-592.

Martimort, D. 2006. "Multi-Contracting Mechanism Design." in Advances in Economics and Econometrics. R. Blundell, W. Newey and T. Persson (eds). 1:56-101.

Meltzer, A. and S. Richard. 1981. "A Rational Theory of the Size of Government." Journal of Political Economy 89:914-927.

Mirrlees, J. 1971. "An Exploration in the Theory of Optimum Income Taxation." Review of Economic Studies 38:175-208.

Myerson, R. 1993. "Incentives to Cultivate Favored Minorities Under Alternative Electoral Systems." American Political Science Review 87(4):856-869.

Osborne, M. and A. Rubinstein. 1994. A course in Game Theory. MIT Press, Cambridge, MA.

Osborne, M. and A. Slivinski. 1996. "A Model of Political Competition With CitizenCandidates." Quarterly Journal of Economics 111:65-96.

Persson, T. and G. Tabellini. 2000. Political Economics: Explaining Economic Policy. Cambridge Massachusetts.

Roberts, K. 1977. "Voting over Income Tax Schedules." Journal of Public Economics 8:329-340.

Roemer, J.E. 1999. "The Democratic Political Economy of Progressive Income Taxation." Econometrica 134:1-19.

Roemer, J.E. 2011a. "The political economy of income taxation under asymmetric information: the two-type case." SERIEs: Journal of the Spanish Economic Association

Roemer, J.E. 2011b. "A theory of income taxation where politicians focus upon core and swing voters." Social Choice and Welfare 36:383-421.

Saez, E. 2001. "Using Elasticities to Derive Optimal Income Tax Rates." Review of Economic Studies 68:205-229. 
Sahuguet, N. and N. Persico. 2006. "Campaign spending regulation in a model of redistributive politics." Economic Theory 28:95-124.

Sheshinski, E. 1972. "The Optimal Linear Income-tax." Review of Economic Studies 39:297-302.

\section{Appendix}

\section{A Proofs}

Proof of Lemma 2. The first round of elimination is exactly as in the proof Lemma 1. implying that politician 0 will not make offers strictly smaller than $\underline{h}$ or strictly larger than $\bar{v}_{L}^{1}$.

Second round of elimination. Given this behavior of politician 0, we now show that politician 1 will not choose an offer belonging to $\left.] \underline{v}_{L}^{1}, \underline{h}\right]$. (i) If politician 0 chooses an offer $v_{L}^{0}>\underline{h}^{2}$, an offer $\left.\left.v_{L}^{1^{\prime}} \in\right] \underline{v}_{L}^{1}, \underline{h}\right]$, and the offer $v_{L}^{1}=\underline{v}_{L}^{1}$ both yield a vote share of $f_{H}$ for politician 1. (ii) Now suppose that politician 0 chooses an offer $v_{L}^{0} \in\left[\underline{h}, \underline{h}^{2}\right]$. In this case, offer $v_{L}^{1^{\prime}}$, and the offer $v_{L}^{1}=\underline{v}_{L}^{1}$ both imply that the low-skilled vote for politician 0 ; however, $v_{L}^{1}=\underline{v}_{L}^{1}$ is the proposal with a maximal chance to get at least the vote of the high-skilled. A symmetric argument implies that politician 1 will not choose an offer belonging to $\left[\bar{h}, \underline{v}_{L}^{1}[\right.$.

Third round of elimination. For politician 0 , any proposal $\left.v_{L}^{0} \in\right] \underline{h}, \bar{h}[$ is dominated by the proposal $v_{L}^{0^{\prime}}=\bar{h}$ : (i) if politician 1 chooses $v_{L}^{1}=\bar{v}_{L}^{1}$, both proposals yield the same vote share of $f_{H}$, (ii) if politician 1 chooses $v_{L}^{1}=\underline{v}_{L}^{1}$, both proposals yield the same vote share of $f_{L}$, and (iii) if politician 1 chooses $\left.v_{L}^{1} \in\right] \underline{h}, \bar{h}\left[\right.$, proposals $v_{L}^{0^{\prime}}$ and $v_{L}^{0}$ ensure that the high-skilled vote for politician 0. However, the proposal $v_{L}^{0^{\prime}}=\bar{h}$ maximizes the probability of also getting the votes of the low-skilled voters. A symmetric argument implies that, for politician 0 , all proposals in $] \underline{h}^{2}, \bar{v}_{L}^{1}$ [ are dominated.

Proof of Proposition 5. Step 1. It proves useful to introduce the following notation: suppose that politician 0 plays an arbitrary mixed strategy $q^{0}=\left(q_{0}^{0}, \ldots, q_{N}^{0}\right)$, then politician 1's payoff from choosing action $v_{L k}^{1}$ equals

$$
\Pi_{k}^{1}=f_{L} \sum_{j=0}^{k-1} q_{j}^{0}+f_{H} \sum_{j=k+1}^{N} q_{j}^{0} .
$$

In particular, this implies that

$$
\Pi_{k-1}^{1}-\Pi_{k}^{1}=-f_{L} q_{k-1}^{0}+f_{H} q_{k}^{0} .
$$


Likewise, we define

$$
\Pi_{k}^{0}=f_{L} \sum_{j=0}^{k-1} p_{j}^{1}+p_{k}^{1}+f_{H} \sum_{j=k+1}^{N} p_{j}^{1},
$$

implying that

$$
\Pi_{k-1}^{0}-\Pi_{k}^{0}=-f_{L} p_{k}^{1}+f_{H} p_{k-1}^{1} .
$$

Step 2. We show that politician 0 plays all actions with positive probability.

(a) Suppose first that $q_{N}^{0}=0$. Then politician 1 has a unique best response, which is to play $v_{L N}^{1}$. However if politician 1 plays this best response with probability 1 , then the unique best response of politician 0 is $v_{L N}^{0}$, thereby contradicting the assumption that $q_{N}^{0}=0$. Hence, it must be true that $q_{N}^{0}>0$.

(b) Now suppose that $q_{N-1}^{0}=0$. By equation (12) and (a) we have that $\Pi_{N-1}^{1}-\Pi_{N}^{1}=$ $f_{H} q_{N}^{0}>0$. This implies that action $v_{L N}^{1}$ is not a best response for politician 1 , hence $p_{N}^{1}=0$. From (13) this implies that $\Pi_{N-1}^{0}-\Pi_{N}^{0}=f_{H} p_{N-1}^{1} \geq 0$. Suppose first that $\Pi_{N-1}^{0}>\Pi_{N}^{0}$. This contradicts that, by $(a), q_{N}^{0}>0$ which requires that $v_{L N}^{0}$ is a best response of politician 0 . Hence, we must have $\Pi_{N-1}^{0}=\Pi_{N}^{0}$. This requires that $p_{N-1}^{1}=0$.

Upon repeating this argument, we find that $\Pi_{N-2}^{0}-\Pi_{N-1}^{0}=f_{H} p_{N-2}^{1} \geq 0$, which requires that $p_{N-2}^{1}=0$.

If we repeat the argument further we ultimately conclude that $p_{k}^{1}=0$, for all $k$, thereby contradicting that $\sum_{k=0}^{N} p_{k}^{1}=1$. Hence, it must be true that $q_{N-1}^{0}>0$.

(c) Now suppose that $q_{N-2}^{0}=0$. By equation $(12)$ and $(b)$ we have that $\Pi_{N-2}^{1}-\Pi_{N-1}^{1}=$ $f_{H} q_{N-1}^{0}>0$. This implies that action $v_{L N-1}^{1}$ is not a best response for politician 1 , hence $p_{N-1}^{1}=0$. From 13 this implies that $\Pi_{N-2}^{0}-\Pi_{N-1}^{0}=f_{H} p_{N-2}^{1} \geq 0$. Suppose first that $\Pi_{N-2}^{0}>\Pi_{N-1}^{0}$. This contradicts that, by $(b), q_{N-1}^{0}>0$ which requires that $v_{L N-1}^{0}$ is a best response of politician 0 . Hence, we must have $\Pi_{N-2}^{0}=\Pi_{N-1}^{0}$. This requires that $p_{N-2}^{1}=0$. Upon repeating the argument, we find that $p_{N-3}^{1}=0, p_{N-4}^{1}=0$, etc.

Also, by part $(a), v_{L N}^{0}$ is also a best response of politician 0 , implying $\Pi_{N-1}^{0}=\Pi_{N}^{0}$, or, equivalently, $\Pi_{N}^{0}-\Pi_{N-1}^{0}=f_{L} p_{N}^{1}=0$, hence $p_{N}^{1}=0$.

Again, we conclude that $p_{k}^{1}=0$, for all $k$, thereby contradicting that $\sum_{k=0}^{N} p_{k}^{1}=1$.

(d) Upon repeating this argument further, we establish that we must have $q_{k}^{0}>0$, for all $k$.

Step 3. Politician 0 is willing to play all actions only if $\Pi_{k-1}^{0}-\Pi_{k}^{0}=0$, for all $k$. Given equation (13) this requires that

$$
p_{k}^{1}=\frac{f_{H}}{f_{L}} p_{k-1}^{1} \text {. }
$$


Equation (14) implies, in particular, that politician 1 must choose all his actions with positive probability. Politician 1 is willing to do so only if $\Pi_{k-1}^{1}-\Pi_{k}^{1}=0$, for all $k$. Given equation 12 this requires that

$$
q_{k}^{0}=\frac{f_{L}}{f_{H}} q_{k-1}^{0} .
$$

Equations 14 and 15 imply in particular that $p_{k}^{1}=\left(\frac{f_{H}}{f_{L}}\right)^{k} p_{0}^{1}$, where $p_{0}^{1}=\frac{1}{\sum_{k=0}^{N}\left(\frac{f_{H}}{f_{L}}\right)^{k}}$. and that $q_{k}^{0}=\left(\frac{f_{L}}{f_{H}}\right)^{k} q_{0}^{0}$, where $q_{0}^{0}=\frac{1}{\sum_{k=0}^{N}\left(\frac{f_{L}}{f_{H}}\right)^{k}}$.

Proof of Corollary 1. Statement i) follows upon observing that

$$
q_{l}^{0}=\frac{\left(\frac{f_{L}}{f_{H}}\right)^{l}}{\sum_{k=0}^{N}\left(\frac{f_{L}}{f_{H}}\right)^{k}} .
$$

Let $l \leq N-1$, the fact that $f_{L}>f_{H}$ implies that $q_{N-1}^{0}$ is an upper bound for $q_{l}^{0}$. A repeated application of L'Hospital's rule yields, $\lim _{N \rightarrow \infty} q_{N-1}^{0}=0$. Consider instead $\lim _{N \rightarrow \infty} q_{N}^{0}$. Now a repeated application of L'Hospital's rule yields $\lim _{N \rightarrow \infty} q_{N}^{0}=1$.

To see that ii) is true, note that, since $f_{H}<f_{L}$,

$$
\lim _{N \rightarrow \infty} p_{0}^{1}=\lim _{N \rightarrow \infty} \frac{1}{\sum_{k=0}^{N}\left(\frac{f_{H}}{f_{L}}\right)^{k}}=1-\frac{f_{H}}{f_{L}} .
$$

We therefore have that

$$
\lim _{N \rightarrow \infty} p_{N}^{1}=\lim _{N \rightarrow \infty}\left(\frac{f_{H}}{f_{L}}\right)^{N} p_{0}^{1}=\left(1-\frac{f_{H}}{f_{L}}\right) \lim _{N \rightarrow \infty}\left(\frac{f_{H}}{f_{L}}\right)^{N}=0 .
$$

\section{B Very small quality differences}

In the body of the text, we characterized the political equilibrium for the cases of large, intermediate, and small quality differences. In the following, we will look at even smaller quality differences. For the formal definition of the degree of smallness, the following shorthand notation will prove convenient:

$$
\underline{h}:=h\left(\underline{v}_{L}^{1}\right), \underline{h}^{2}:=h(\underline{h}), \ldots \text { and } \bar{h}:=h^{-1}\left(\bar{v}_{L}^{1}\right), \bar{h}^{2}:=h^{-1}(\bar{h}), \ldots
$$

where the dependence of these functions on the quality difference $b^{1}$ is suppressed. We can now associate a quality difference of order $k \in \mathbb{N}$, by the properties $\bar{h}^{k-1} \geq \underline{h}^{k-1}$ and $\underline{h}^{k}>\bar{h}^{k}$.

If, in relation to the cases in the body of the text, we decrease the quality difference further, we may run into open set problems. To illustrate this, we will, in the following, 
study one more case explicitly. Once this case is understood, we explain how the analysis generalizes to arbitrarily small quality differences.

Henceforth, we interpret the strategy spaces $\tilde{S}^{0}$ and $\tilde{S}^{1}$ as arbitrarily fine discretizations of the sets of possible utility promises. For instance, $\tilde{S}^{0}$ will be taken to be a finite ordered set, $\tilde{S}^{0}=\left\{s_{0}^{0}, \ldots, s_{z}^{0}\right\}$, with $s_{k}^{0}=\underline{v}_{L}(0)+\frac{k}{z}\left(\bar{v}_{L}(0)-\underline{v}_{L}(0)\right)$, where $z$ is an arbitrarily large integer. Moreover, to simplify the exposition, we make the following assumptions about the strategy sets $\tilde{S}^{0}$ and $\tilde{S}^{1}$ : Whenever $\underline{h}^{k} \in\left[\underline{v}_{L}^{j}, \bar{v}_{L}^{j}\right]$, then $\underline{h}^{k} \in \tilde{S}^{j}$. Likewise, $\bar{h}^{k} \in\left[\underline{v}_{L}^{j}, \bar{v}_{L}^{j}\right]$ implies $\underline{h}^{k} \in \tilde{S}^{j}$. Moreover, we assume that $\bar{v}_{L}^{1} \in \tilde{S}^{0}$. Also, for any $v_{L}$, we will denote henceforth by $\left(v_{L}\right)_{+}^{j}$ the smallest element in $\tilde{S}^{j}$ that is strictly larger than $v_{L}$, and by $\left(v_{L}\right)_{-}^{j}$ the largest element that is strictly smaller than $v_{L}$.

In the following, we will decrease the quality successively in a sequence of steps. The next case to consider, after the case of a small quality difference in the body of the text, is defined by the following properties: $\underline{h}^{2}>\bar{h}^{2}$ and $\bar{h}^{2}>\underline{h}$; see Figure 9 .

Lemma B.1 Suppose that $\underline{h}^{2}>\bar{h}^{2}$ and $\bar{h}^{2}>\underline{h}$. Then, the support of politician 1 's equilibrium strategy is contained in $\left\{\underline{v}_{L}^{1},(\underline{h})_{+}^{1},(\bar{h})_{-}^{1}, \bar{v}_{L}^{1}\right\}$. The support of politician 0 's equilibrium strategy is contained in $\left\{\underline{h}, \underline{h}^{2}, \bar{h}, \bar{v}_{L}^{1}\right\}$.

Proof The first two rounds of elimination are exactly as in the proof Lemma 2, implying that politician 0 will not make offers strictly smaller than $\underline{h}$, or strictly larger than $\bar{v}_{L}^{1}$, and that politician 1 will not make offers in $\left.\underline{v}_{L}^{1}, \underline{h}\right] \cup\left[\bar{h}, \bar{v}_{L}^{1}[\right.$. Third round of elimination. For politician 0 , any proposal $\left.v_{L}^{0} \in\right] \underline{h}, \underline{h}^{2}$ [ is dominated by the proposal $v_{L}^{0^{\prime}}=\underline{h}^{2}$ : (i) if politician 1 chooses $v_{L}^{1}=\bar{v}_{L}^{1}$, both proposals yield the same vote share of $f_{H}$; (ii) if politician 1 chooses $v_{L}^{1}=\underline{v}_{L}^{1}$, both proposals yield the same vote share of $f_{L}$; and (iii) if politician 1 chooses $\left.v_{L}^{1} \in\right] \underline{h}, \bar{h}\left[\right.$, proposals $v_{L}^{0^{\prime}}$ and $v_{L}^{0}$ ensure that the high-skilled vote for politician 0. However, the proposal $v_{L}^{0^{\prime}}=\underline{h}^{2}$ maximizes the probability of also getting the votes of the low-skilled voters. A symmetric argument implies that, for politician 0 , all proposals in $] \underline{h}, \bar{v}_{L}^{1}[$ are dominated.

Fourth round of elimination. For politician 1 , any proposal $v_{L}^{1} \in\left[\underline{h}^{2},(\bar{h})_{-}^{1}\right.$ [ is dominated by the proposal $v_{L}^{1^{\prime}}=(\bar{h})_{-}^{1}$ : (i) if politician 0 plays $v_{L}^{0} \geq \bar{h}$, both proposals yield a vote share of $f_{H}$, (ii) if politician 0 plays $v_{L}^{0}<\underline{h}^{2}$, both proposals yield a vote share of $f_{L}$, (iii) if politician 0 plays $v_{L}^{0} \in\left[\underline{h}^{2}, \bar{h}\left[\right.\right.$, then the proposal $v_{L}^{1^{\prime}}=(\bar{h})_{-}^{1}$ gives a vote share of $f_{L}$ against any such proposal, whereas $v_{L}^{1} \in\left[\bar{h}^{2},(\bar{h})_{-}^{1}\right.$ [ yields 0 against some of those proposals. A symmetric argument implies that, for politician 1, all proposals in $\left.] \underline{h}_{+}, \underline{h}^{2}\right]$ are dominated.

Fifth round of elimination. For politician 0, any proposal $\left.v_{L}^{0} \in\right] \underline{h}^{2}, \bar{h}[$ is dominated by the proposal $v_{L}^{0^{\prime}}=\bar{h}$ : (i) if politician 1 plays $v_{L}^{1} \in\left\{\underline{v}_{L}^{1},(\underline{h})_{+}^{1}\right\}$, both proposals yield a vote share of $f_{L}$; (ii) if politician 1 plays $v_{L}^{1}=\bar{v}_{L}^{1}$, both yield a vote share of $f_{H}$, (iii) if 
politician 1 plays $v_{L}^{1}=(\bar{h})_{-}^{1}$, then a proposal $\left.v_{L}^{0} \in\right] \underline{h}^{2}, \bar{h}\left[\right.$ yields a vote share of $f_{H}$, whereas the proposal $v_{L}^{0^{\prime}}=\bar{h}$ yields a vote share of 1 . To be more precise, for politician 0 , all proposals in $\tilde{S}^{0} \cap\left[(\bar{h})_{-}^{1}, \bar{h}\right]$ are payoff-equivalent and dominate the proposals in $\underline{h}^{2},(\bar{h})_{-}^{1}[$. Since our assumptions ensure that $\bar{h} \in \tilde{S}^{0} \cap\left[(\bar{h})_{-}^{1}, \bar{h}\right]$, we may without loss of generality assume that, in case of a tie between $\bar{h}$ and some other proposal very close to it, politician 0 will eliminate the latter, but not the former.

Proposition B.1 Suppose that $\underline{h}^{2}>\bar{h}^{2}$ and $\bar{h}^{2}>\underline{h}$. Then, there is unique equilibrium, which is as follows:

i) Politician 1 plays $\underline{v}_{L}^{1}$ with probability $p_{0}^{1},(\underline{h})_{+}^{1}$ with probability $p_{1}^{1}=\frac{f_{H}}{f_{L}} p_{0}^{1},(\bar{h})_{-}^{1}$ with probability $p_{2}^{1}=\left(\frac{f_{H}}{f_{L}}\right)^{2} p_{0}^{1}$, and $\bar{v}_{L}^{1}$ with probability $p_{3}^{1}=\left(\frac{f_{H}}{f_{L}}\right)^{3} p_{0}^{1}$, where $p_{0}^{1}=$ $\frac{1}{\sum_{k=0}^{3}\left(\frac{f_{H}}{f_{L}}\right)^{k}}$.

ii) Politician 0 plays $\underline{h}$ with probability $q_{0}^{0}, \underline{h}^{2}$ with probability $q_{1}^{0}=\frac{f_{L}}{f_{H}} q_{0}^{0}, \bar{h}$ with probability $q_{2}^{0}=\left(\frac{f_{L}}{f_{H}}\right)^{2} q_{0}^{0}$, and $\bar{v}_{L}^{1}$ with probability $q_{3}^{0}=\left(\frac{f_{L}}{f_{H}}\right)^{3} q_{0}^{0}$, where $q_{0}^{0}=\frac{1}{\sum_{k=0}^{3}\left(\frac{f_{L}}{f_{H}}\right)^{k}}$.

Proof The proof follows from a characterization of the mixed-strategy equilibria of the normal form game in Table 4 , which is a special case of Proposition 5 .

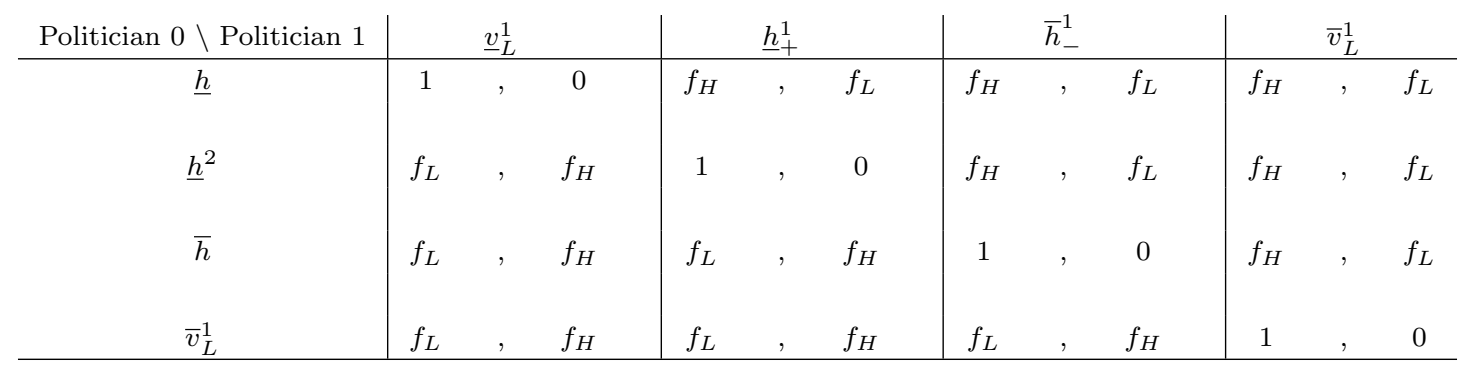

Table 4: The normal form game if $\underline{h}^{2}>\bar{h}^{2}$ and $\bar{h}^{2}>\underline{h}$.

Going from the case with $\bar{h}^{2} \leq \underline{h}$ to the case with $\bar{h}^{2}>\underline{h}$ has implications that are by now familiar: for each politician, the number of actions that survive the iterated elimination of weakly dominated strategies increases by 1 . Politician 0 is more likely to win and randomizes in such a way that proposals that are more attractive to the low-skilled are played with a larger probability. By contrast, the bad politician makes proposals that are more attractive to the high-skilled with a larger probability. The cases differ, however, in the outcome of the elimination procedure. Given that $\bar{h}^{2}>\underline{h}$, each politician has exactly four actions that are played with positive probability, whereas under the assumption $\bar{h}^{2} \leq \underline{h}$ one "action" was a collection of payoff-equivalent proposals. Another difference between the cases is that now we need the assumption of a discrete set of policy proposals 
in order to ensure the existence of equilibrium. A reader who is interested in the details may check that the fourth round of elimination in the proof of Lemma B.1 would not work with an unrestricted set of policy proposals.

We now go on and decrease the quality difference between the two politicians further. The next case to consider is defined by $\bar{h}^{2} \geq \underline{h}^{2}$ and $\underline{h}^{3}>\bar{h}^{3}$, with two subcases, depending on whether or not $\bar{h}^{3} \leq \underline{h}^{2}$. From there on, we could move to a case characterized by $\bar{h}^{3} \geq \underline{h}^{3}$ and $\underline{h}^{4}>\bar{h}^{4}$, etc. Our reason for not presenting formal Lemmas and Propositions about these cases is that they would be straightforward generalization of the results above. In particular, each decrease in the quality difference implies, for each of the two politicians, one additional proposal that survives the iterated elimination of weakly dominated strategies. Moreover, whatever the quality difference, the good politician 0 draws his proposals from a bounded segment of his frontier. The smallest proposal that is made with positive probability is $\underline{h}$ and the largest one is $\bar{v}_{L}^{1}$. Politician 1 makes the smallest proposal on his frontier, $\underline{v}_{L}^{1}$, and the largest one, $\bar{v}_{L}^{1}$, with positive probability, etc. More generally, this establishes that a larger index $k$ in the order of quality differences is associated with (i) a smaller quality difference, and (ii) a larger number $N_{k}$ of actions that are played by either politician in equilibrium. Letting the quality difference vanish is therefore equivalent to letting $k$, and hence the number of actions played in equilibrium, go to $\infty$.

\section{An alternative interpretation of quality differences: Charisma}

The Pareto-frontiers in Figure 1 reflect differences in the revenue requirement. The outer frontier is based on a revenue requirement of $b^{0}=0$, and the inner frontier is based on a revenue requirement $b^{1}>0$. Hence, the quality difference between the two politicians takes the form of a cost differential. Politician 1 is more costly to the voters in the sense that government consumption is higher.

In the following, we briefly describe an alternative interpretation of the model in which the quality difference between the two politicians is unrelated to economic outcomes. Suppose, for the sake of the argument, that politician 0 is more charismatic than politician 1 , but that they can both propose all the tax schedules that correspond to the inner frontier in Figure 1. Now consider a voter of type $t \in\{L, H\}$, with a promised utility level of $v_{t}$. Following the literature, we assume that the voter's total utility, reflecting charisma measured by $\delta>0$ and economic outcomes, equals $v_{t}+\delta$, if the proposal is made by the charismatic politician and equals $v_{t}$, otherwise. 
Graphically, this means that the total utility promises that can be made by the good politician are obtained by an outward translation of the inner frontier along a 45-degreeline. The resulting pair of Pareto-frontiers has the same qualitative properties as the ones in Figure 1. In particular, it satisfies conditions (8) - 10). Since these are all that matters for the formal analysis below, our results do not depend on whether or not quality differences are interpreted as "real" differences in economic outcomes or simply as voter attitudes with no direct economic meaning. 


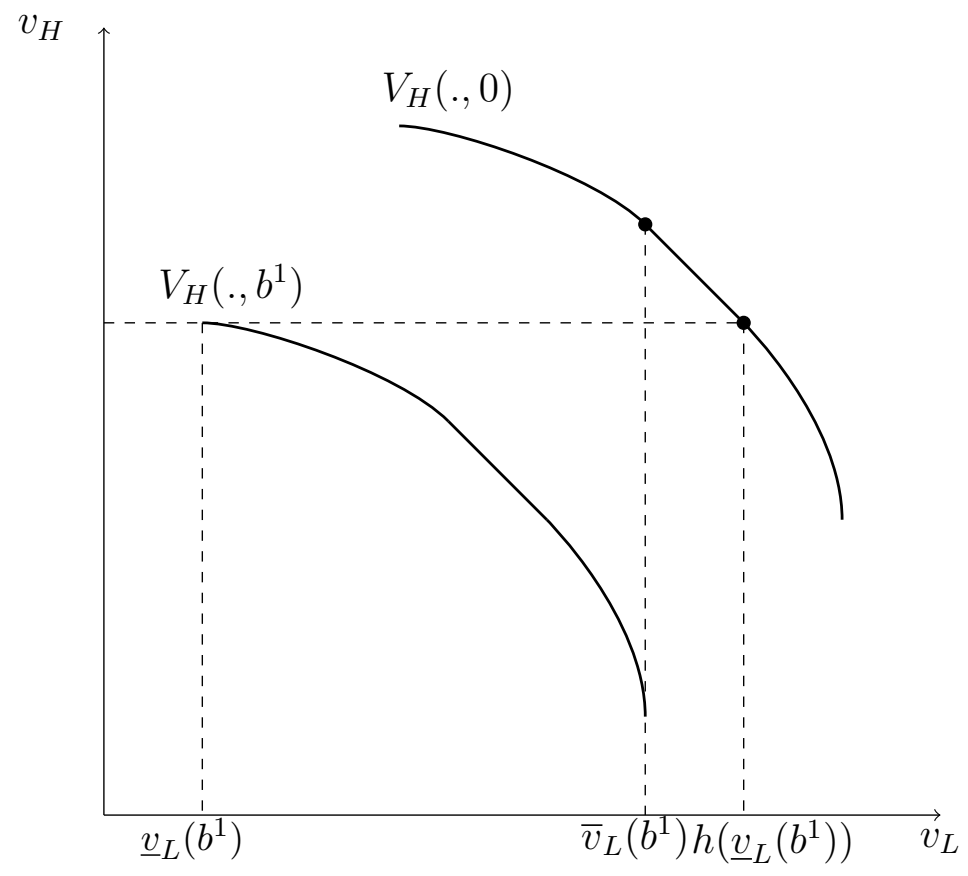

Figure 6: Second-best Pareto-frontiers in case of a large quality difference.

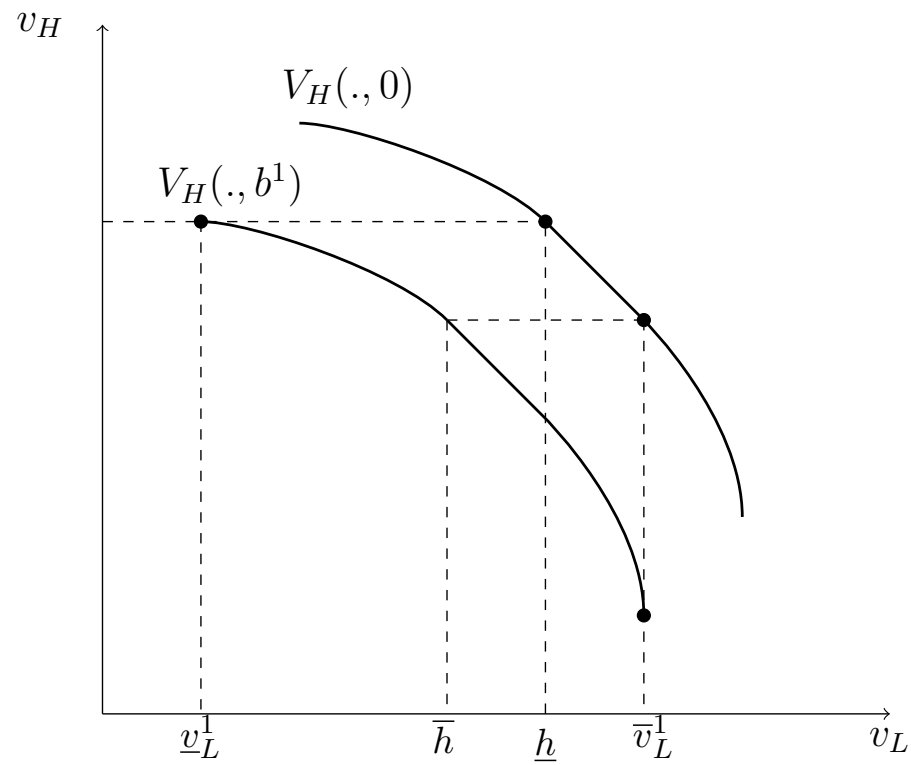

Figure 7: Second-best Pareto-frontiers of politicians for an intermediate quality difference. 


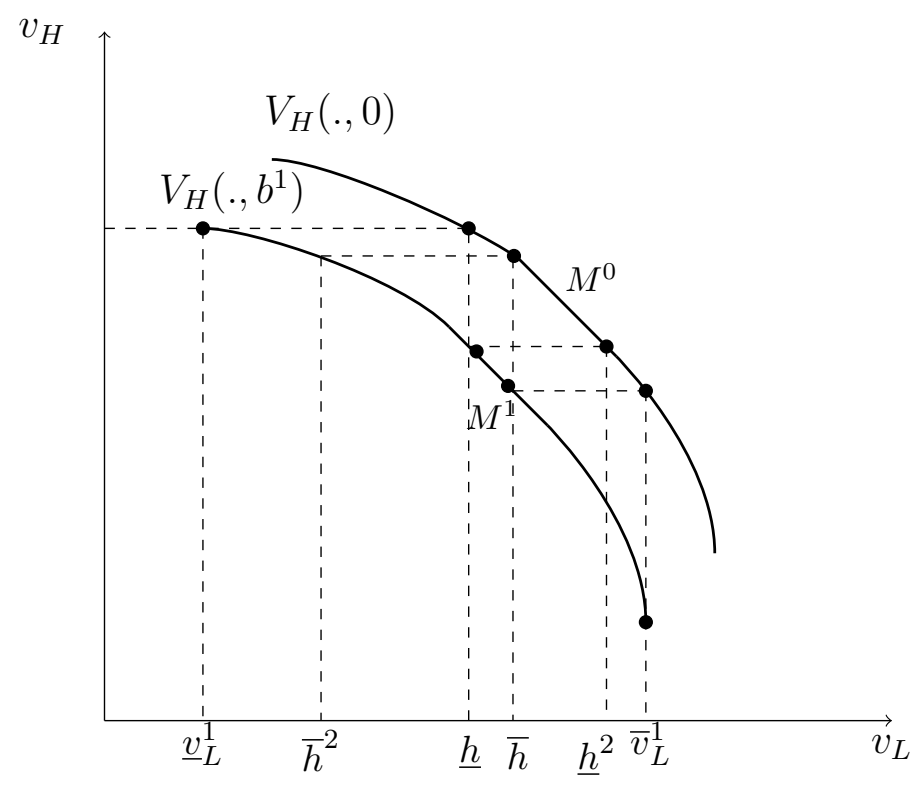

Figure 8: Second-best Pareto-frontiers of politicians for a small quality difference.

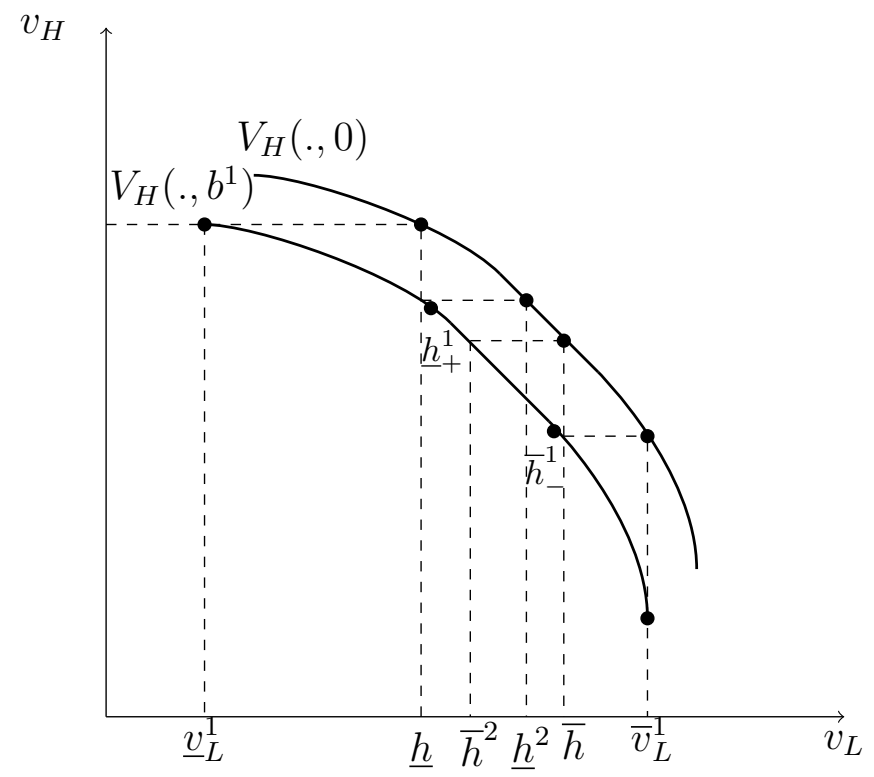

Figure 9: Second-best Pareto-frontiers if $\underline{h}^{2}>\bar{h}^{2}$ and $\bar{h}^{2}>\underline{h}$. 